\title{
Representation of the Antarctic Circumpolar Current in the CMIP5 climate models and future changes under warming scenarios
}

\author{
A. J. S. Meijers, ${ }^{1}$ E. Shuckburgh, ${ }^{1}$ N. Bruneau, ${ }^{1}$ J.-B. Sallee, ${ }^{1}$ T. J. Bracegirdle, ${ }^{1}$ \\ and Z. Wang ${ }^{2}$ \\ Received 31 July 2012; revised 21 September 2012; accepted 16 October 2012; published 11 December 2012
}

[1] The representation of the Antarctic Circumpolar Current (ACC) in the fifth

Coupled Models Intercomparison Project (CMIP5) is generally improved over CMIP3.

The range of modeled transports in the historical (1976-2006) scenario is reduced

(90-264 Sv) compared with CMIP3 (33-337 Sv) with a mean of $155 \pm 51 \mathrm{~Sv}$.

The large intermodel range is associated with significant differences in the ACC density structure. The ACC position is accurately represented at most longitudes, with a small $\left(1.27^{\circ}\right)$ standard deviation in mean latitude. The westerly wind jet driving the ACC is biased too strong and too far north on average. Unlike CMIP3 there is no correlation between modeled ACC latitude and the position of the westerly wind jet. Under future climate forcing scenarios (2070-2099 mean) the modeled ACC transport changes by between -26 to $+17 \mathrm{~Sv}$ and the ACC shifts polewards (equatorwards) in models where the transport increases (decreases). There is no significant correlation between the ACC position change and that of the westerly wind jet, which shifts polewards and strengthens. The subtropical gyres strengthen and expand southwards, while the change in subpolar gyre area varies between models. An increase in subpolar gyre area corresponds with a decreases in ACC transport and an equatorward shift in the ACC position, and vice versa for a contraction of the gyre area. There is a general decrease in density in the upper $1000 \mathrm{~m}$, particularly equatorwards of the ACC core.

Citation: Meijers, A. J. S., E. Shuckburgh, N. Bruneau, J.-B. Sallee, T. J. Bracegirdle, and Z. Wang (2012), Representation of the Antarctic Circumpolar Current in the CMIP5 climate models and future changes under warming scenarios, J. Geophys. Res., 117, C12008, doi:10.1029/2012JC008412.

\section{Introduction}

[2] The Antarctic Circumpolar Current (ACC) and the southern limb of the MOC are intimately linked, and are driven by a combination of wind and buoyancy forcing [Marshall and Radko, 2003; Marshall and Speer, 2012]. Strong midlatitude westerly winds blow along the zonally continuous ACC. These winds drive a strong northward Ekman transport, as well as acting to upwell deep circumpolar waters at high latitudes where there is an Ekman divergence. These combined effects act to tilt isopycnals meridionally, which in turn drives the strong ACC current of $134 \pm 11 \mathrm{~Sv}\left(1 \mathrm{~Sv}=10^{6} \mathrm{~m}^{3} \mathrm{~s}^{-1}\right)$ [Cunningham et al., 2003]. Circumpolar Deep Water (CDW) upwelled south of the ACC undergoes a transformation process forced by interior mixing and interactions with the atmosphere and sea ice. Some is

\footnotetext{
${ }^{1}$ British Antarctic Survey, Cambridge, UK.

${ }^{2}$ School of Marine Sciences, Nanjing University of Information Science and Technology, Nanjing, China.

Corresponding author: A. J. S. Meijers, British Antarctic Survey, High Cross, Madingley Road, Cambridge CB30ET, UK. (andmei@bas.ac.uk)

C2012. American Geophysical Union. All Rights Reserved. 0148-0227/12/2012JC008412
}

transported northward, in the 'upper' MOC cell, freshened by precipitation and eventually encounters the subtropical front on the northern side of the ACC where it is subducted to form SubAntarctic Mode Water (SAMW) and Antarctic Intermediate Water (AAIW). This water is eventually transported at depth into the subtropical gyres, and forms one of the main sequestration pathways for anthropogenic carbon dioxide into the ocean interior [Sabine et al., 2004; Mignone et al., 2006; Sallée et al., 2012]. Some of the upwelled CDW that is transported poleward south of the ACC eventually contributes to Antarctic Bottom Water (AABW) through a complex process of water mass transformations driven by mixing with shelf waters, brine rejection and intense winter time convection at specific locations around the Antarctic coastline. AABW is the densest anywhere in the ocean and sinks to abyssal depths and spreads northwards as part of the 'lower' MOC cell, extending past the equator and renewing the interior ocean.

[3] How this system changes on interannual and interdecadal timescales is poorly known. The zonal winds have been observed to have moved poleward and strengthened over the last 30 years [Marshall, 2003], and during the satellite altimetry period (1992-present) the jets of the ACC 
have also shifted poleward by approximately one degree [Sokolov and Rintoul, 2009]. The ACC has also been observed to be warming [Gille, 2008] and freshening [Helm et al., 2010], particularly in the upper $1000 \mathrm{~m}$ around the SubAntarctic Front, but also at depths below $2000 \mathrm{~m}$ [Purkey and Johnson, 2010]. Meijers et al. [2011] shows that this is largely an adiabatic change due to the southward movements of the fronts, but there is also a significant diabatic contribution of freshwater from outside the ACC. North of the ACC Roemmich et al. [2007] showed that the Pacific subtropical gyre has increased in strength since 1993, probably due to increased wind stress curl over this basin, while to the south possible changes to the subpolar gyre waters have also been observed [Rintoul, 2007]. Despite these changes, however, Böning et al. [2008] finds that the ACC isopycnal slope has changed little over several decades while Meredith et al. [2004] and Rintoul and Sokolov [2001] show that the interannual ACC variability is of the order 7-10 Sv and that present observational techniques are not sensitive enough to resolve any long term trends.

[4] Modeling studies [e.g., Hallberg and Gnanadesikan, 2006; Farneti et al., 2010; Morrison et al., 2011; Meredith et al., 2012] have shown that the ACC is sensitive to the strength of buoyancy forcing and the strength and latitude of the zonal wind stress, but its characteristics are also strongly influenced by the underlying bathymetry, internal mixing, vertical stratification, the subtropical and subpolar gyre positions and mesoscale eddies. Model resolution has been shown in numerous studies [e.g., Farneti et al., 2010; Abernathey et al., 2011] to also be very important for both the representation of the ACC and in determining its sensitivity to forcing effects. This is mainly through the resolution of mesoscale eddies, which act to modify the meridional overturning circulation [Hallberg and Gnanadesikan, 2006], reduce ACC sensitivity to wind stress [Hogg and Blundell, 2006] and transfer momentum vertically [Ivchenko et al., 1996]. Buoyancy forcing is also difficult to resolve, particularly for the formation of AABW which occurs in very small geographic regions as a result of a complex combination of seaice, wind and bathymetric interactions that are far beyond the present ability of climate models to reproduce.

[5] The complexity of the ACC and computational constraints means that efforts to model it in coarse resolution coupled climate models have met with mixed success. The Coupled Model Intercomparison Project phase 3 (CMIP3) [Meehl et al., 2007] coupled general circulation models used in the Intergovernmental Panel on Climate Change (IPCC) Fourth Assessment Report (AR4) [Solomon et al., 2007] produced a very wide spread of values for key ACC characteristics such as transport, core latitude and meridional density structure. The ACC transport in particular varied by an order of magnitude (37-337 Sv) [Russell et al., 2006; Sen Gupta et al., 2009]. Russell et al. [2006] demonstrated that many of the modeled ACC differences could be attributed to differences in modeled heat flux and salinity gradients across the ACC, along with the strength of wind stress fields at the latitude of Drake Passage. The choice of eddy parameterization scheme has likewise been shown to have a strong impact on the strength of the modeled ACC, particularly those models using the Gent and McWilliams [Gent and McWilliams, 1990] parameterization where the thickness diffusivity $\kappa$ is a prescribed constant, rather than varying as a function of isopycnal gradient [Kuhlbrodt et al., 2012].

[6] The response of the ACC to a doubling of atmospheric $\mathrm{CO}_{2}$ also varied across CMIP3 models, but broadly similar patterns did emerge [Sen Gupta et al., 2009], with the subtropical gyres accelerating and expanding poleward [Cai, 2006], the zonal wind jet moving polewards and intensifying [Fyfe and Saenko, 2006; Bracegirdle et al., 2008] and the ACC core shifting polewards. Similarly, there was a broad warming of the upper $1000 \mathrm{~m}$, strongest in the ACC core and extending to below $2000 \mathrm{~m}$ south of the region of upwelling CDW. The change in the ACC transport, however, was extremely varied between models, with some increasing by up to $27 \mathrm{~Sv}$, while others decreased by over $29 \mathrm{~Sv}$. Wang et al. [2011] attributed this variability to differing responses of the subtropical and particularly the subpolar gyres between models, which acted to change the area of eastward ACC flow.

[7] This study describes the representation of the ACC and Southern Ocean in the CMIP5 [Taylor et al., 2012] ensemble of coupled climate models and their response to climate forcing scenarios. The CMIP5 ensemble of models are improved over earlier generations of models in several important areas. Firstly the resolutions of the models in the ocean and atmosphere are generally higher (mostly $<1.5^{\circ} \times 1^{\circ}$ ), although none yet resolve eddies, and the parameterization of sub grid scale ocean eddies is more sophisticated in most models. More models include coupled carbon cycles and biogeochemistry (earth system models) to more correctly capture climate feedback loops, and cryosphere coupling is enhanced. The atmospheric chemistry is similarly improved, with all models now including stratospheric ozone, and more models physically resolving the upper atmosphere with 'high top' models.

[8] Here we describe the present day 'historical' representation of the ACC and factors influencing it in 23 of the CMIP5 models, including the ACC strength, latitude, and meridional mean density structure, the representation of the subpolar and subtropical gyres, and the strength and position of the zonal wind stress and wind stress curl. We also examine how these ACC properties and influences change under the future Representative Concentration Pathways (RCP) 4.5 and RCP8.5, where 4.5 and 8.5 indicate the respective estimated change in radiative forcing in the year 2100 . We aim to provide a baseline study that describes the ACC and relevant changes under climate forcing for as many models as possible, for future studies to use in dynamical examinations of the model physics and processes that condition the ACC and control its changes. Three companion papers examine other aspects of the CMIP5 Southern Ocean. T. J. Bracegirdle et al. (Assessment of surface winds over the Atlantic, Indian and Pacific Ocean sectors of the Southern Hemisphere in CMIP5 models: Historical bias, forcing response, and state dependency, submitted to Journal of Geophysical Research, 2012; hereinafter referred to as Bracegirdle et al., submitted manuscript, 2012) look at the representation and change of the surface winds over the Southern Hemisphere from an atmospheric perspective, while J.-B. Sallée et al. (Assessment of the Southern Ocean mixed-layer depth in CMIP5 models: Historical bias and forcing response, submitted to Journal of Geophysical Research, 2012; hereinafter referred to as Sallée et al., submitted manuscript, 2012a) and J.-B. Sallée et al. (Assessment of the Southern Ocean water mass circulation and 
Table 1. Details of Ocean Models Used in CMIP5 Analysis of Southern Ocean ${ }^{\mathrm{a}}$

\begin{tabular}{|c|c|c|c|c|c|c|c|}
\hline Model Number & Model Name & HIST & $\mathrm{RCP} 45$ & RCP85 & Vertical & Resolution & ESM \\
\hline 1 & BCC-CSM1-1 & $\mathrm{Y}$ & $\mathrm{Y}$ & $\mathrm{Y}$ & $\mathrm{Z}$ & $1.0 \times 1.0$ & $\mathrm{Y}$ \\
\hline 2 & CanESM2 & $\mathrm{Y}$ & $\mathrm{Y}$ & $\mathrm{Y}$ & $\mathrm{Z}$ & $1.41 \times 0.93$ & $\mathrm{Y}$ \\
\hline 3 & CCSM4 & $\mathrm{Y}$ & $\mathrm{Y}$ & & Z & $1.13 \times 0.53$ & \\
\hline 4 & CNRM-CM5 & $\mathrm{Y}$ & $\mathrm{Y}$ & & Z & $1.0 \times 0.65$ & $\mathrm{Y}$ \\
\hline 5 & CSIRO-Mk3-6-0 & $\mathrm{Y}$ & $\mathrm{Y}$ & & $\mathrm{Z}$ & $1.88 \times 0.93$ & \\
\hline 6 & GFDL-ESM2G & $\mathrm{Y}$ & $\mathrm{Y}$ & $\mathrm{Y}$ & $\mathrm{Z}$ & $1.0 \times 1.0$ & $\mathrm{Y}$ \\
\hline 7 & GFDL-ESM2M & $\mathrm{Y}$ & $\mathrm{Y}$ & $\mathrm{Y}$ & $\mathrm{Z}$ & $1.0 \times 1.0$ & $\mathrm{Y}$ \\
\hline 8 & GISS-E2-H & $\mathrm{Y}$ & & & $\mathrm{Z}$ & $1.0 \times 1.0$ & \\
\hline 9 & GISS-E2-R & $\mathrm{Y}$ & $\mathrm{Y}$ & $\mathrm{Y}$ & Z & $1.25 \times 1.0$ & \\
\hline 10 & HadCM3 & $\mathrm{Y}$ & & & $\mathrm{Z}$ & $1.25 \times 1.25$ & \\
\hline 11 & HadGEM2-CC & $\mathrm{Y}$ & $\mathrm{Y}$ & $\mathrm{Y}$ & $Z$ & $1.0 \times 1.0$ & $\mathrm{Y}$ \\
\hline 12 & HadGEM2-ES & $\mathrm{Y}$ & & $\mathrm{Y}$ & $\mathrm{Z}$ & $1.0 \times 1.0$ & $\mathrm{Y}$ \\
\hline 13 & INMCM4 & $\mathrm{Y}$ & $\mathrm{Y}$ & & $\mathrm{S}$ & $1.0 \times 0.47$ & $\mathrm{Y}$ \\
\hline 14 & IPSL-CM5A-LR & $\mathrm{Y}$ & $\mathrm{Y}$ & $\mathrm{Y}$ & $\mathrm{Z}$ & $1.98 \times 1.30$ & $\mathrm{Y}$ \\
\hline 15 & IPSL-CM5A-MR & $\mathrm{Y}$ & $\mathrm{Y}$ & $\mathrm{Y}$ & $\mathrm{Z}$ & $1.98 \times 1.30$ & $\mathrm{Y}$ \\
\hline 16 & IPSL-CM5B-LR & $\mathrm{Y}$ & $\mathrm{Y}$ & & $\mathrm{Z}$ & $1.98 \times 1.30$ & $\mathrm{Y}$ \\
\hline 17 & MIROC4h & $\mathrm{Y}$ & & & $\mathrm{SZ}$ & & \\
\hline 18 & MIROC5 & $\mathrm{Y}$ & $\mathrm{Y}$ & $\mathrm{Y}$ & $\mathrm{SZ}$ & $1.41 \times 0.78$ & \\
\hline 19 & MIROC-ESM & $\mathrm{Y}$ & $\mathrm{Y}$ & $\mathrm{Y}$ & $\mathrm{SZ}$ & $1.41 \times 0.93$ & $\mathrm{Y}$ \\
\hline 20 & MIROC-ESM-CHEM & $\mathrm{Y}$ & $\mathrm{Y}$ & $\mathrm{Y}$ & $\mathrm{SZ}$ & $1.41 \times 0.93$ & $\mathrm{Y}$ \\
\hline 21 & MPI-ESM-LR & $\mathrm{Y}$ & $\mathrm{Y}$ & $\mathrm{Y}$ & $\mathrm{Z}$ & $1.41 \times 0.89$ & $\mathrm{Y}$ \\
\hline 22 & MRI-CGCM3 & $\mathrm{Y}$ & $\mathrm{Y}$ & $\mathrm{Y}$ & $\mathrm{Z}$ & $1.0 \times 0.5$ & $\mathrm{Y}$ \\
\hline 23 & NorESM1-M & $\mathrm{Y}$ & & $\mathrm{Y}$ & Z & $1.13 \times 0.53$ & $\mathrm{Y}$ \\
\hline
\end{tabular}

${ }^{\mathrm{a}} \mathrm{Y}$ indicates model is available for given scenario. Vertical refers to the vertical coordinate scheme, where $\mathrm{Z}$ indicates depth level and $\mathrm{S}$ sigma coordinates (SZ are hybrids). Resolution is zonal mean ocean grid longitude and latitude differences at $50^{\circ} \mathrm{S}$. ESM (Earth System Model) indicates if model includes a coupled carbon cycle. Note that models 2 and 17 are not included in correlation plots or multi model means in this study.

characteristics in CMIP5 models: Historical bias and forcing response), submitted to Journal of Geophysical Research, 2012; hereinafter referred to as Sallée et al., submitted manuscript, 2012b) examine the Southern Ocean mixed layer depth and water mass characteristics respectively.

[9] This paper is structured as follows. In section 2 the models, data sets and methodologies used in the study are described. Section 3 details the assessment of the modeled ACC mean 'historical' state against both observations and CMIP3 models. This section also examines changes to key ACC metrics under the RCP4.5 and RCP8.5 scenarios. Discussion and conclusions follow in section 4.

\section{Models and Data}

[10] Output from 23 CMIP5 models were used in this study. All models had historical data available, and most had one or both of the RCP4.5 and 8.5 scenarios at the time of writing (Table 1). Required variables were downloaded from the British Atmospheric Data Center (BADC) portal, and variables from both the atmospheric and ocean components were used. These variables were: The surface wind stress components 'tauu' and 'tauv', the ocean velocity components 'uo' and 'vo', and the ocean potential temperature and salinity 'thetao' and 'so'. The MIROC4h and CanESM2 models did not have sufficient velocity data available at the time of writing for ACC or streamfunction metrics to be calculated, but did have 'thetao' and 'so' variables. Models using isopycnal, sigma or hybrid coordinate systems (indicated in Table 1) were interpolated by the authors onto depth levels for ease of comparison. To estimate the representation of the present state of the ocean, monthly means from the 'historical' forcing were averaged over the years 1976-2005 to give 30 year means. The historical scenario is forced by both natural and anthropogenic factors using 20th century variations of important climate drivers. The same data for the two future scenarios,
RCP4.5 (18 models) and RCP8.5 (15 models) were used where available, but the mean was constructed using monthly means from the years 2070-2099. RCP4.5 represents a medium $\mathrm{CO}_{2}$ mitigation scenario, while RCP8.5 represents a high emissions scenario [Moss et al., 2010; Taylor et al., 2012]. Both scenarios include a full range of anthropogenic forcing factors, including green house gasses, aerosols and land use [Meinshausen et al., 2011]. Differences between the 21 st and 20th centuries are defined in this paper as differences between the 30 years means described above.

[11] Observational data sets were used to compare the results of the historical runs with real world values. The CSIRO Atlas of Regional Oceans (CARS09) [Ridgway et al., 2002] was used to estimate the climatological state of the temperature and salinity in the ocean interior. The Large and Yeager climatological wind stress values were used to estimate the strength and mean latitude of the westerly wind jet core, as well as the magnitude and latitude of the wind stress curl maxima over the subtropical gyres [Large and Yeager, 2012]. Finally the AVISO CNES-CLS09 mean sea surface height between 1993-1999 [Rio et al., 2011] was used as an approximation of the volume transport streamfunction following Russell et al. [2006] and the climatological position of the ACC core was calculated from this as described below.

[12] At the time of writing the ocean barotropic streamfunction and residual overturning streamfunction were not available for a sufficient number of models to provide a useful inter comparison. Instead, the barotropic streamfunction was approximated by calculating the vertically integrated volume transport in the zonal direction, and cumulatively summing this value from Antarctica northwards, giving the volume transport streamfunction. This was then offset such that ACC values were positive and the South American continent had a value of $0 \mathrm{~Sv}$. Unfortunately, the residual overturning streamfunction cannot be easily calculated with the available data, as monthly means are insufficient to estimate the eddy 

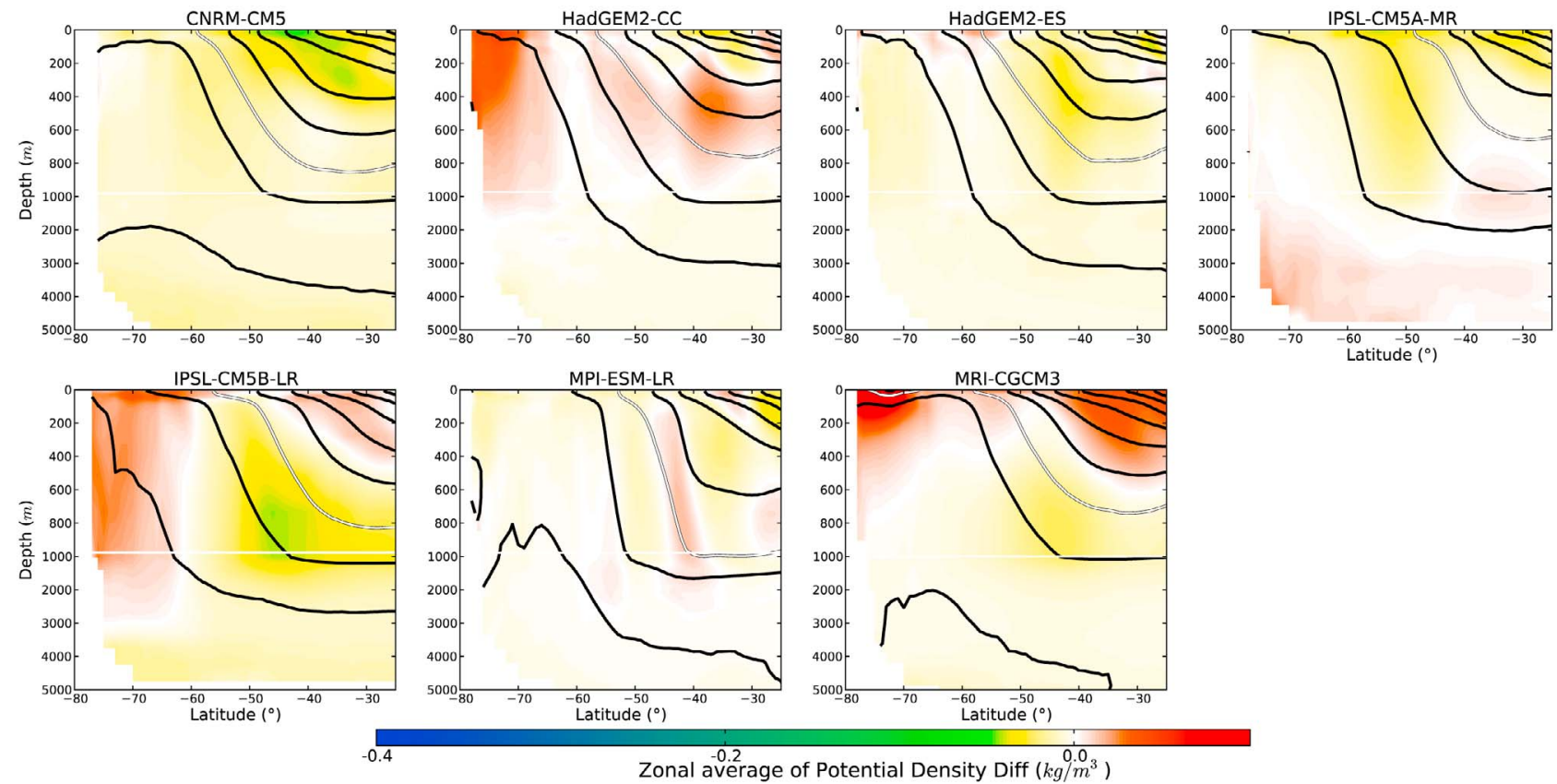

Figure 1. Zonal mean change of potential density $\left(\sigma_{2}\right)$ between the 1900-1930 mean and 1970-1999 mean of pre-industrial model control runs. White contour is $36 \mathrm{kgm}^{-3}$. Contour interval is $0.5 \mathrm{kgm}^{-3}$. Note expanded y-axis for upper $1000 \mathrm{~m}$.

driven component of the overturning, and soit is excluded from this study.

[13] Drake Passage transports were calculated as the difference in streamfunction between the points $68^{\circ} \mathrm{W}, 54^{\circ} \mathrm{S}$ and $60^{\circ} \mathrm{W}, 64.7^{\circ} \mathrm{S}$. The position of the ACC core is defined here as in Sen Gupta et al. [2009]. It was calculated from the streamfunction by finding the mean latitude of the upper $50 \%$ of zonal transport $\left(\frac{\partial \psi}{\partial y}\right)$ values at each longitude inside the range of ACC streamfunction values ( 0 to the Drake Passage transport value). The mean ACC latitude was then taken as the mean of the core latitudes across all longitudes.

\subsection{Model Drift}

[14] As the ocean equilibrium time scale is of the order of several thousand years, it is not yet computationally practical to integrate coupled climate models for the length of time needed to eliminate model drift. Unfortunately, at the time of writing pre-industrial control runs were only available for seven models in the analysis data set, and so we have not subtracted the drift from our results. We note, however, that the zonal mean drift in potential density for the available preindustrial control runs between the mean of years 1901-1930 and 1970-1999 is approximately an order of magnitude smaller than the changes over the 21 st century (Figure 1). This is particularly the case in the upper $1000 \mathrm{~m}$ where the greatest changes from atmospheric climate forcing is felt in the ocean. It is also worth noting that the strongest model drift in several models (HadGEM2-CC, IPSL-CM5B-LR and MRI-CGCM3) (up to $0.1 \mathrm{kgm}^{-3} \mathrm{C}^{-1}$ ) is in the opposite sense (increasing density) to the lightening trends seen in the forced runs. In these cases model drift may reduce the apparent change in the upper ocean under climate forcing. In general, however, both the irregular pattern and small magnitude of model drifts are such that they will not greatly influence projected changes which are stronger and have a characteristic fingerprint across most models. In the ocean below $2000 \mathrm{~m}$ model drift is much weaker (typically around $0.01 \mathrm{kgm}^{-3} \mathrm{C}^{-1}$ in magnitude), but so is the projected change under climate forcing. Most models have a weak drift towards lighter densities, which is similar in sign and magnitude to the change under climate forcing. The exception to this is the IPSLCM5A-MR which tends to become denser. Under the RCP4.5 and RCP8.5 scenarios the IPSL-CM5A-MR has practically no deep change, while most other models lighten by around $0.02-0.03 \mathrm{kgm}^{-3} \mathrm{C}^{-1}$. The model drift is approximately equal in magnitude to climate forced changes in weakly ventilated parts of the water column, but is much smaller where ventilation does occur and therefore is unlikely to alias important future signals driven by surface forcing. The influence of model drift on ACC metrics such as position, strength and northern and southern boundaries is typically less than the internal variability of the models (not shown). The only exception to this is the IPSL-CM5B-LR that has a significant increase in ACC transport $(>10 \mathrm{~Sv})$ and a poleward ACC movement of over four degrees. The development group note that this model has known biases due to a lack of tuning.

\section{Results}

\subsection{ACC Metrics}

\subsubsection{Historical State Skill}

[15] In this section we examine the representation of key ACC diagnostics in the historical CMIP5 model runs. These diagnostics include direct estimates of the ACC strength and position, as well as properties that have been shown in previous studies [Fyfe and Saenko, 2006; Sen Gupta et al., 

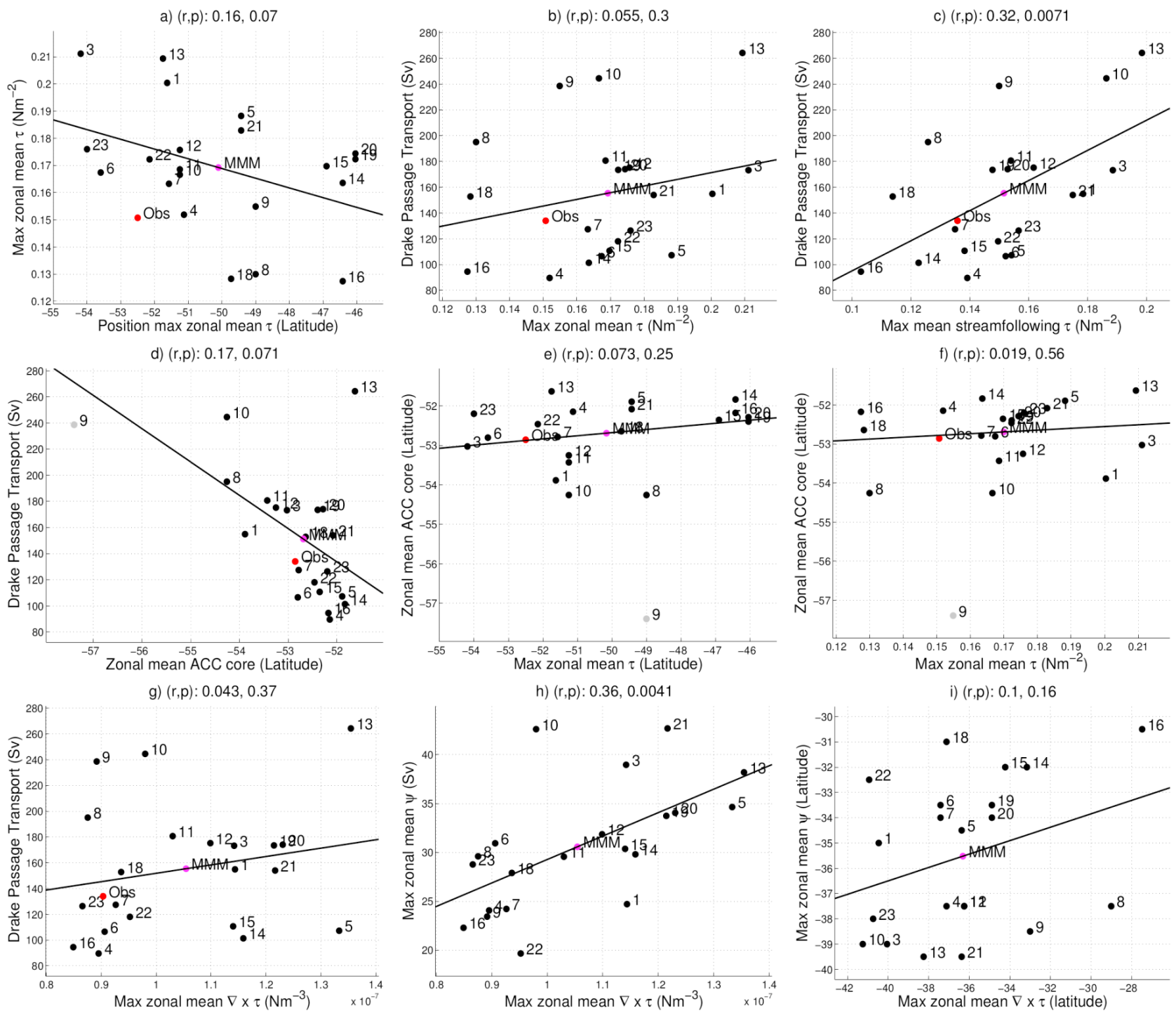

Figure 2. Scatter plots for 30 year averages (1976-2005) of maximum zonally averaged wind stress vs (a) maximum zonal mean stress latitude and (b) Drake Passage transport. Maximum wind stress averaged along ACC streamlines vs (c) ACC transport. (d) Zonal mean ACC core latitude vs Drake Passage transport, (e) maximum mean zonal wind stress latitude and (f) maximum zonal wind stress. Maximum zonal mean wind stress curl vs (g) Drake Passage transport and $(\mathrm{h})$ maximum zonal mean subtropical gyre strength. (i) Maximum zonal mean wind stress curl latitude vs latitude of maximum zonal mean subtropical gyre strength. Model numbers (Table 1) are given, as is the linear regression with $\mathrm{r}$ and $\mathrm{p}$ values. MMM indicates multi model mean, while Obs shows observational values where available. Grey shaded points are excluded from the calculation of multi model mean and regressions.

2009; Wang et al., 2011] to have an influence on ACC representation, such as wind stress, wind stress curl and the strength and position of the subtropical gyres. The model mean values for these diagnostics for the historical scenario between 1976-2005 are show in Figure 2, along with values estimated from observations or reanalysis products.

[16] The westerly wind jet has been shown in CMIP3 to be strongly correlated with both the latitude of the ACC core and its strength [Russell et al., 2006; Sen Gupta et al., 2009]. Here (Figure 2a) we see that there is a widespread of zonal wind stress maxima and the latitudes of these maxima. These tend to be biased stronger $\left(0.023 \pm 0.020 \mathrm{Nm}^{-2}\right)$ and further equatorwards $\left(2.96 \pm 2.39^{\circ}\right)$ than observations, although not significantly at the $90 \%$ confidence level (Table 2 ). There is also a tendency for models with stronger zonal wind stress maxima to be positioned further polewards, but this intermodel relationship is not as strong as in CMIP3. Similarly, the positive relationship between maximum zonal wind stress and ACC strength (measured as transport through Drake Passage) is statistically insignificant (Figure 2b) in the CMIP5 ensemble, although it becomes stronger if maximum mean wind stress in the direction of the transport streamfunction is used rather than zonal winds (Figure 2c).

[17] The modeled transport through Drake Passage has large intermodel variability, with a multimodel mean of $155 \pm 51 \mathrm{~Sv}$ (Table 3), which lies within the observational 
Table 2. Mean Model Differences and Intermodel Standard Deviations for Key ACC Parameters Between 1976-2005 and 2070-2099

\begin{tabular}{lcccccccc}
\hline & ACC Trans. & ACC Lat. & $\tau_{\max }$ & $\tau_{\max }$ Lat. & $(\nabla \times \tau)_{\max } \times 10^{-8}$ & $(\nabla \times \tau)_{\max }$ Lat. & $\psi_{\min }$ & $\psi_{\min }$ Lat. \\
\hline HIST-obs & $21.3 \pm 50.5$ & $-0.06 \pm 1.27$ & $0.019 \pm 0.023$ & $2.40 \pm 2.59$ & $1.51 \pm 1.61$ & $2.18 \pm 3.64$ & - \\
RCP4.5-HIST & $-1.9 \pm 10.1$ & $0.07 \pm 0.36$ & $0.009 \pm 0.007$ & $-0.35 \pm 0.80$ & $0.50 \pm 0.37$ & $-0.30 \pm 0.67$ & $0.38 \pm 1.74$ & $-1.88 \pm 2.13$ \\
RCP8.5-HIST & $-2.7 \pm 9.8$ & $-0.01 \pm 0.44$ & $\mathbf{0 . 0 2 5} \pm \mathbf{0 . 0 0 8}$ & $-1.62 \pm 1.36$ & $\mathbf{1 . 1 0} \pm \mathbf{0 . 4 0}$ & $-\mathbf{2 . 3 5} \pm \mathbf{2 . 6 9}$ & $2.18 \pm 2.81$ & $-\mathbf{3 . 2 0} \pm \mathbf{2 . 4 1}$ \\
\hline
\end{tabular}

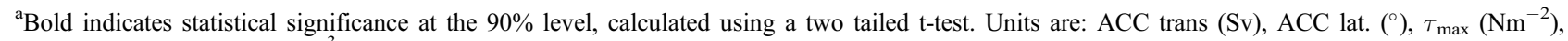
$\tau_{\max }$ lat. $\left(^{\circ}\right),(\nabla \times \tau)_{\max }\left(\mathrm{Nm}^{-3}\right),(\nabla \times \tau)_{\max }$ lat. $\left({ }^{\circ}\right), \psi_{\max }(\mathrm{Sv})$ and $\psi_{\max }$ lat. $\left(^{\circ}\right)$.

range of 134-164 Sv [Cunningham et al., 2003; Griesel et al., 2012]. However, there are significant outliers, such as the HadCM3, INMCM4 and GISS-E2-R models which have ACC transports in the range 230-270 Sv, while the IPSL-CM5B-LR and CNRM-CM5 both have transports of less than $100 \mathrm{~Sv}$ (Table 3). Despite the large range of transports $(90-263 \mathrm{~Sv})$ the CMIP5 ensemble is an improvement over CMIP3, which had a range of between 33-337 Sv, mean 144.6 \pm 74.1 Sv [Sen Gupta et al., 2009]. The interannual internal variability of the ACC transport over the historical period is shown for each model in Table 3. This ranges from 1.4 to $5.0 \mathrm{~Sv}$, and so is similar to high resolution model interannual variability estimates [Meredith et al., 2004].

[18] The mean latitude of the ACC core, calculated as described in section 2 , is quite accurately represented by the models (Figure $2 \mathrm{~d}$ ). The models tend to be biased slightly equatorwards $\left(0.47 \pm 2.64^{\circ}\right.$, Table 2$)$ but are typically within one degree of the observed position of $52.9^{\circ} \mathrm{S}$. The major exception to this is the GISS-E2-R, which is biased polewards by over four degrees. This model also has extremely high ACC transports and, as discussed in section 3.3, a poor representation of the meridional water mass structure. The ACC position has very small internal interannual variability across all models $\left(0.06-0.026^{\circ}\right)$ over the historical period, probably due to strong topographic constraints. A notable exception is the MPI-ESM-LR which has an interannual standard deviation of $2.76^{\circ}$. There is no apparent relationship between the mean latitude of the ACC core and either the value or position of the maximum zonal mean wind stress (Figures $2 \mathrm{e}$ and $2 \mathrm{f}$ ). This is in contrast to CMIP3 where there was a strong $(r=0.7)$, statistically significant positive relationship across models between the position of the ACC and zonal mean wind stress maximum [Sen Gupta et al., 2009].

[19] The wind stress curl over the subtropical gyres has a strong influence on the strength and position of the subtropical gyres, which themselves impact the ACC by defining its northern boundary and influencing the meridional density gradient and mixed layer depths (Sallée et al., submitted manuscript, 2012a). The modeled mean zonal wind stress curl maximum is generally larger than the observed value, but there is considerable spread between models (Table 2). The wind stress curl is not significantly correlated with the strength of the ACC, although there is a general tendency for models with stronger wind stress curl maxima to have stronger ACCs (Figure 2g), as may be expected given the weak correlation with wind stress. The wind stress curl maxima is significantly correlated with the mean strength of the subtropical gyres (Figure 2h), although there are substantial differences between modeled gyre strengths (20-43 Sv). The most significant outliers are the HadCM3 and MPI-ESM-LR, with mean gyre strengths of over $42 \mathrm{~Sv}$. Finally, there is a weak positive relationship $(\mathrm{r}, \mathrm{p}=0.1,0.16)$ between the latitude of the maximum zonal mean wind stress curl and the latitude of the mean subtropical gyre centers. This contrasts with CMIP3 where there was a much stronger $(\mathrm{r}, \mathrm{p}=0.67,0.01)$ correlation between models [Sen Gupta et al., 2009]. The gyres tend to be further poleward in CMIP5 and there is a generally bimodal distribution where models either have a mean gyre center between $30-35^{\circ} \mathrm{S}$ or between $37-40^{\circ} \mathrm{S}$. This separation is largely due to differences in the latitude of the Aghulas retroflection between models, discussed further in section 3.2.

Table 3. Model Internal Variability for Key ACC Parameters Over Annual Means Between 1976-2005

\begin{tabular}{|c|c|c|c|c|c|c|}
\hline Model Name & ACC Trans. & ACC Lat. & $\tau_{\max }$ & $\tau_{\max }$ Lat. & $(\nabla \times \tau)_{\max } \times 10^{-6}$ & $(\nabla \times \tau)_{\max }$ Lat. \\
\hline BCC-CSM1-1 & $154.9 \pm 2.3$ & $-53.9 \pm 0.08$ & $0.204 \pm 0.011$ & $-50.1 \pm 1.21$ & $0.143 \pm 0.011$ & $-38.6 \pm 1.3$ \\
\hline CCSM4 & $173.2 \pm 1.5$ & $-52.6 \pm 0.09$ & $0.213 \pm 0.011$ & $-53.5 \pm 0.95$ & $0.162 \pm 0.013$ & $-42.1 \pm 1.6$ \\
\hline CNRM-CM5 & $89.6 \pm 2.4$ & $-52.2 \pm 0.13$ & $0.158 \pm 0.012$ & $-50.6 \pm 1.35$ & $0.141 \pm 0.010$ & $-37.4 \pm 2.0$ \\
\hline CSIRO-Mk3-6-0 & $107.3 \pm 1.4$ & $-49.6 \pm 0.14$ & $0.197 \pm 0.011$ & $-49.0 \pm 1.06$ & $0.163 \pm 0.010$ & $-38.2 \pm 1.3$ \\
\hline GFDL-ESM2G & $106.5 \pm 1.9$ & $-52.9 \pm 0.08$ & $0.173 \pm 0.011$ & $-52.2 \pm 0.89$ & $0.125 \pm 0.007$ & $-37.9 \pm 1.3$ \\
\hline GFDL-ESM2M & $127.4 \pm 1.5$ & $-52.8 \pm 0.11$ & $0.169 \pm 0.009$ & $-51.5 \pm 1.16$ & $0.125 \pm 0.006$ & $-38.0 \pm 1.3$ \\
\hline GISS-E2-H & $195.4 \pm 2.0$ & $-54.3 \pm 0.09$ & $0.140 \pm 0.011$ & $-50.0 \pm 1.85$ & $0.110 \pm 0.006$ & $-35.3 \pm 2.2$ \\
\hline GISS-E2-R & $238.6 \pm 1.8$ & $-57.4 \pm 0.06$ & $0.164 \pm 0.011$ & $-49.3 \pm 1.43$ & $0.121 \pm 0.008$ & $-36.7 \pm 1.9$ \\
\hline HadCM3 & $244.5 \pm 4.0$ & $-53.5 \pm 0.10$ & $0.173 \pm 0.009$ & $-50.2 \pm 1.12$ & $0.123 \pm 0.005$ & $-39.0 \pm 1.2$ \\
\hline IPSL-CM5A-LR & $101.3 \pm 5.0$ & $-48.8 \pm 0.26$ & $0.174 \pm 0.011$ & $-45.5 \pm 1.61$ & $0.135 \pm 0.007$ & $-35.5 \pm 1.3$ \\
\hline IPSL-CM5A-MR & $110.7 \pm 1.9$ & $-49.1 \pm 0.09$ & $0.183 \pm 0.014$ & $-46.7 \pm 1.36$ & $0.144 \pm 0.009$ & $-36.8 \pm 1.4$ \\
\hline IPSL-CM5B-LR & $94.5 \pm 3.5$ & $-48.9 \pm 0.09$ & $0.140 \pm 0.008$ & $-46.6 \pm 1.69$ & $0.110 \pm 0.006$ & $-33.4 \pm 1.3$ \\
\hline MIROC5 & $152.8 \pm 2.6$ & $-51.4 \pm 0.28$ & $0.143 \pm 0.008$ & $-48.9 \pm 2.22$ & $0.161 \pm 0.010$ & $-37.5 \pm 1.4$ \\
\hline MIROC-ESM & $173.5 \pm 2.8$ & $-51.4 \pm 0.09$ & $0.180 \pm 0.009$ & $-46.7 \pm 1.40$ & $0.132 \pm 0.006$ & $-35.6 \pm 1.1$ \\
\hline MIROC-ESM-CHEM & $174.0 \pm 1.7$ & $-51.3 \pm 0.08$ & $0.179 \pm 0.009$ & $-46.9 \pm 1.12$ & $0.132 \pm 0.005$ & $-35.6 \pm 0.9$ \\
\hline MPI-ESM-LR & $153.9 \pm 2.5$ & $-52.1 \pm 2.76$ & $0.191 \pm 0.007$ & $-48.7 \pm 1.53$ & $0.151 \pm 0.007$ & $-37.2 \pm 1.3$ \\
\hline MRI-CGCM3 & $118.0 \pm 1.8$ & $-52.6 \pm 0.16$ & $0.180 \pm 0.012$ & $-51.8 \pm 0.98$ & $0.147 \pm 0.010$ & $-40.0 \pm 1.8$ \\
\hline NorESM1-M & $126.4 \pm 1.5$ & $-51.8 \pm 0.10$ & $0.177 \pm 0.010$ & $-53.2 \pm 0.94$ & $0.121 \pm 0.007$ & $-40.6 \pm 1.3$ \\
\hline Multimodel mean & $146.8 \pm 46.5$ & $-52.4 \pm 2.75$ & $0.174 \pm 0.023$ & $-49.5 \pm 2.4$ & $0.140 \pm 0.023$ & $-37.5 \pm 2.1$ \\
\hline
\end{tabular}

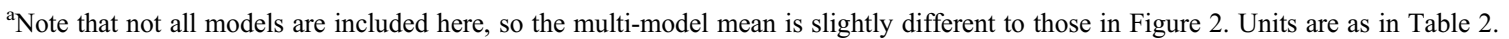



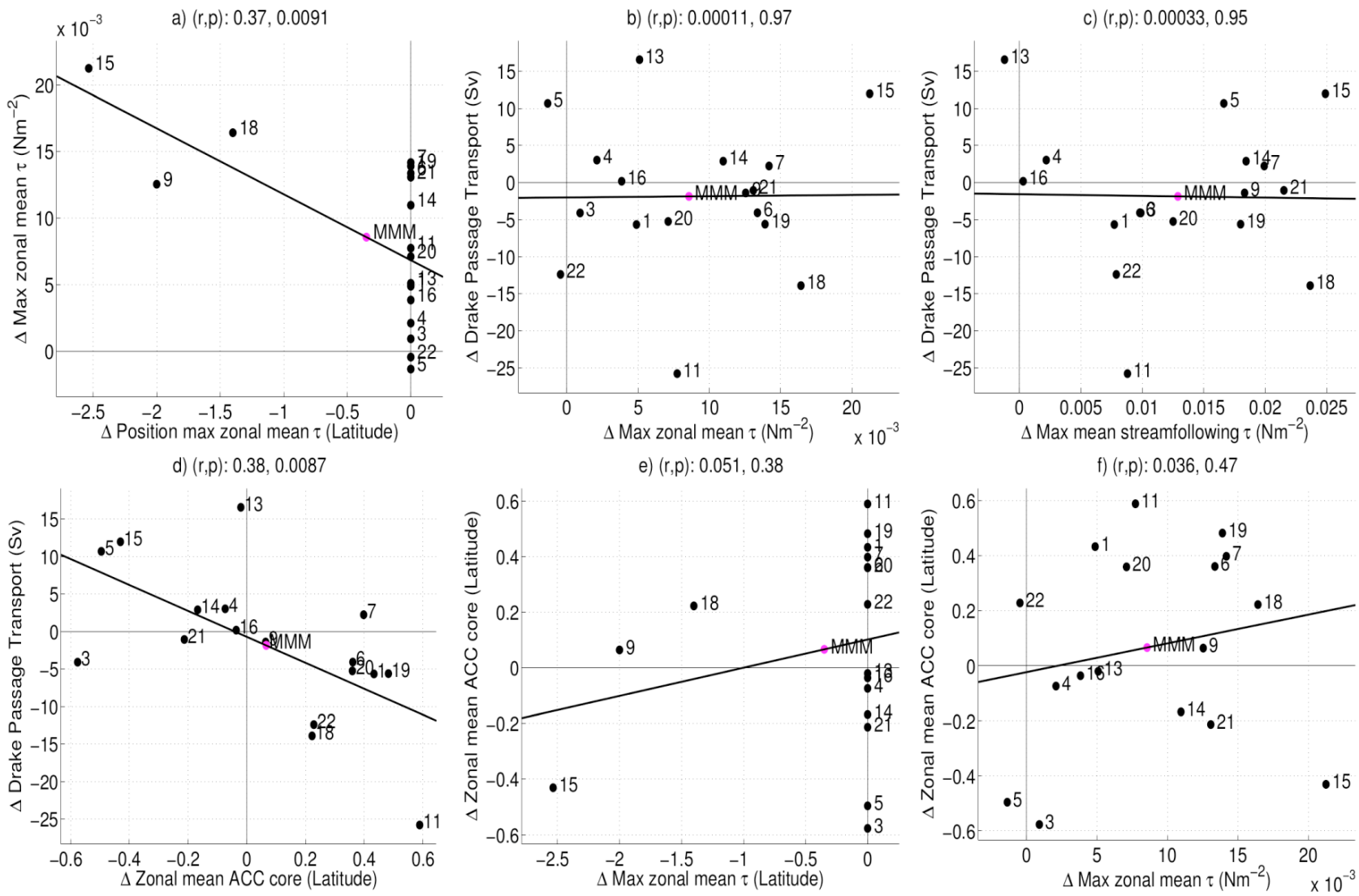

g) $(r, p): 0.18,0.091$
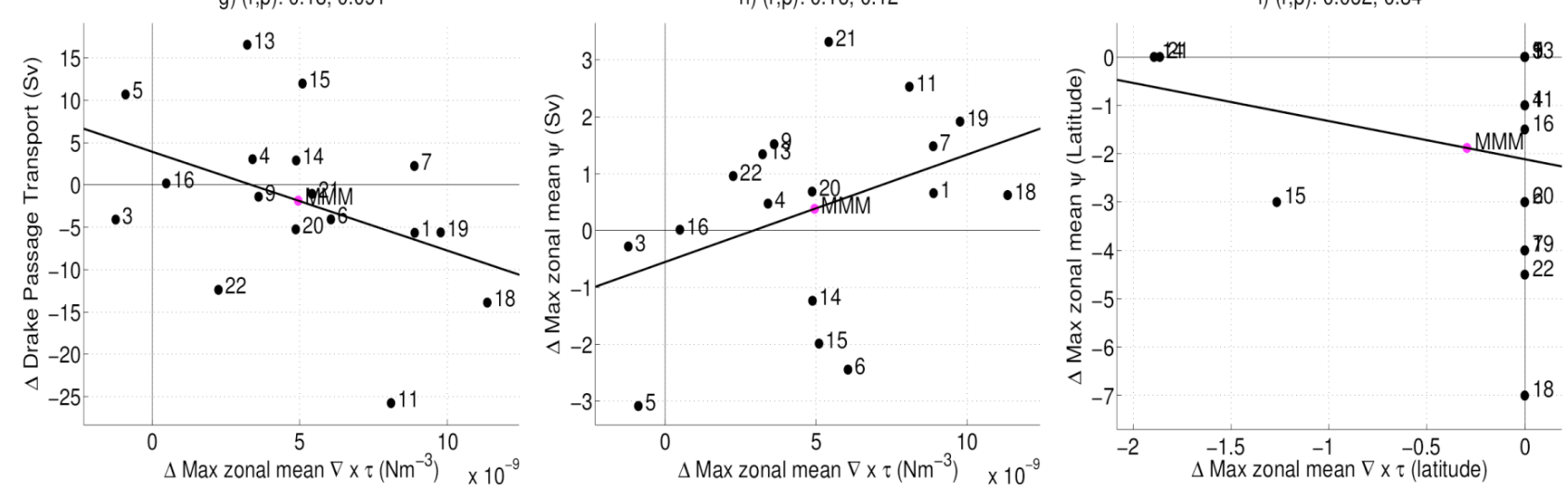

Figure 3. As for Figure 2 but showing differences between RCP4.5 end of the 21 st century run (2070 2099) and the historical mean (1976-2005). Note that not all models shown in Figure 2 have RCP4.5 data available.

\subsubsection{Changes Under Climate Forcing Scenarios}

[20] There are significant and coherent changes to the ACC metrics between the end of the 20th century (19762006) and the end of the 21st century (2070-2099) under both the RCP4.5 (Figure 3) and RCP8.5 (Figure 4) scenarios. The maximum mean zonal wind stress increases in both scenarios by $0.009 \pm 0.006 \mathrm{Nm}^{-2}$ and $0.025 \pm 0.008 \mathrm{Nm}^{-2}$ respectively (Table 2). Only two models (CSIRO-Mk3-6-0 and MRI-CGCM3) have a (small) reduction in mean zonal wind stress under RCP4.5, and none do under RCP8.5. In both scenarios the mean latitude of the maximum mean zonal wind stress either remains constant or shifts polewards. Only three models show a shift under RCP4.5 (GISS-
E2-R, IPSL-CM5A-MR and MIROC5), while only four do not shift under RCP8.5 (BCC-CSM1-1,GFDL-ESM2G, MRI-CGCM3 and NorESM1-M). Under RCP8.5 the poleward shift in the wind stress maximum of $1.62 \pm 1.36^{\circ} \mathrm{S}$ is statistically significant (at the 90\% level) between models, and is larger than the model internal interannual variability (less than $1.5^{\circ}$ typically) and has a strong positive correlation with the increase in wind stress (Figure 4a). The IPSLCM5A-MR is again a significant outlier, increasing in strength by greater than $0.04 \mathrm{Nm}^{-2}$ and shifting poleward by over five degrees. The robust poleward shift and increase in strength of the zonal wind stress maximum is consistent with previous studies of CMIP3 models [Russell et al., 2006; 
a) (r.p): $0.51,0.0027$

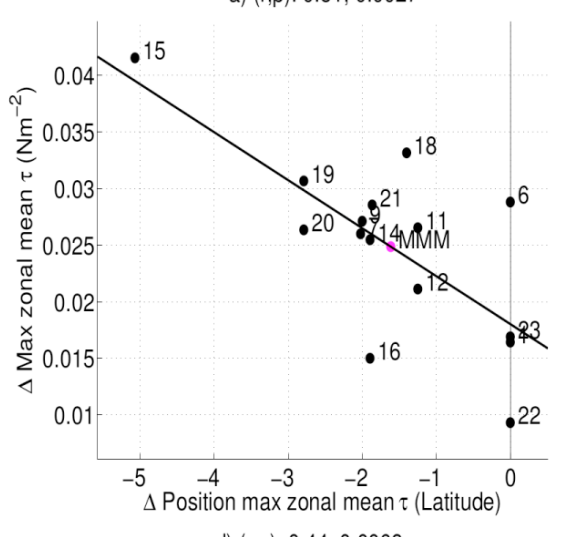

d) $(r, p): 0.44,0.0068$

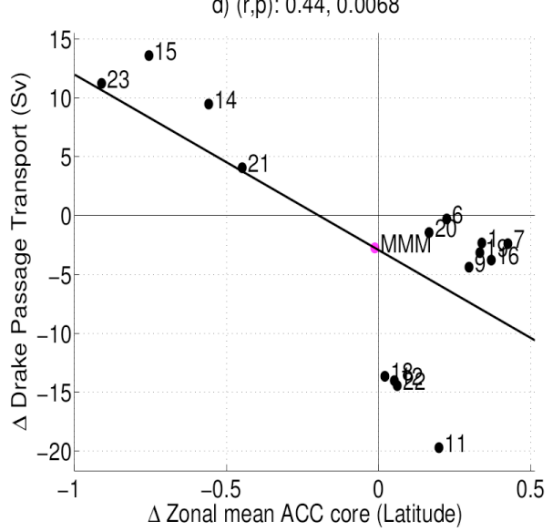

g) $(r, p): 0.0061,0.78$

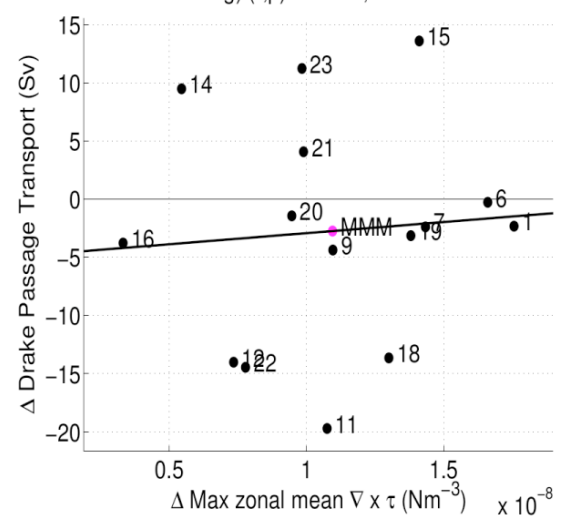

b) $(r, p): 0.08,0.31$

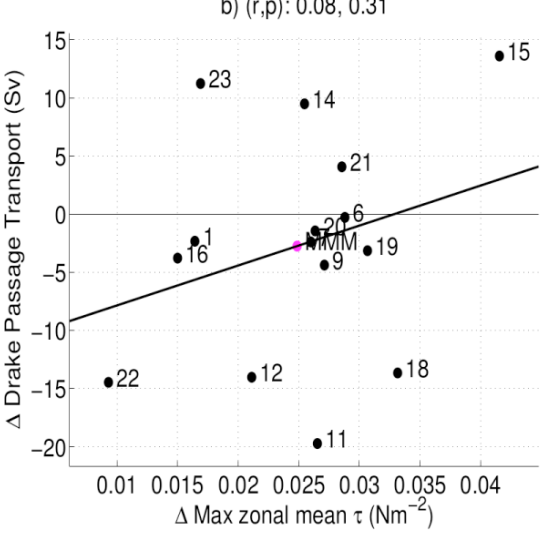

e) $(r, p): 0.034,0.51$

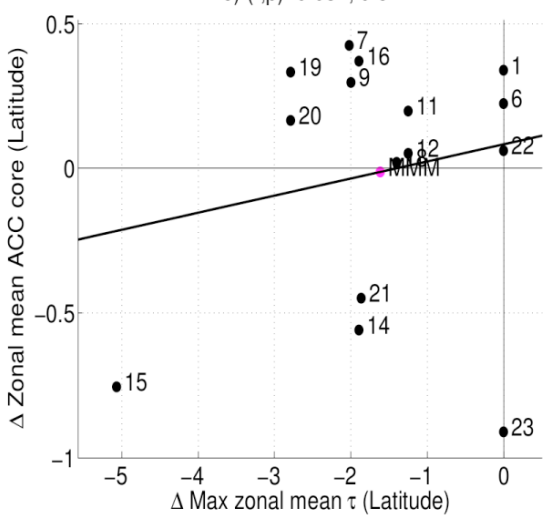

h) $(r, p): 0.011,0.71$

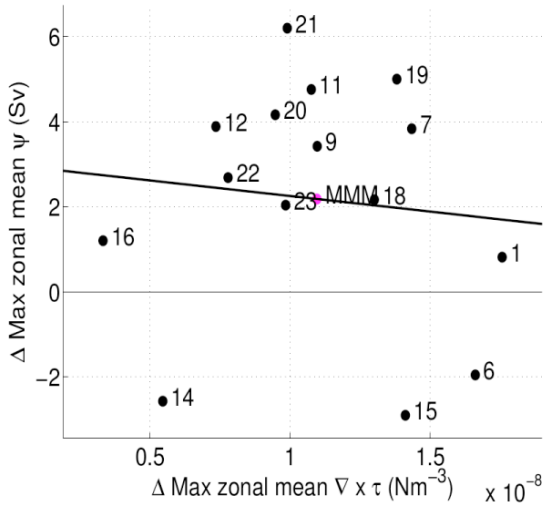

c) $(r, p): 0.16,0.15$

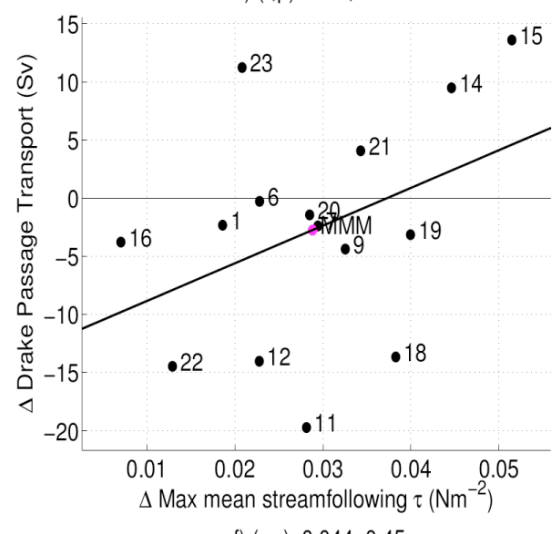

f) $(r, p): 0.044,0.45$

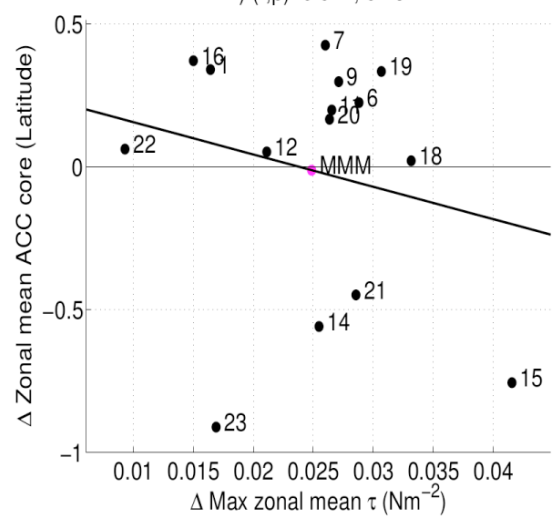

i) $(r, p): 0.00088,0.92$

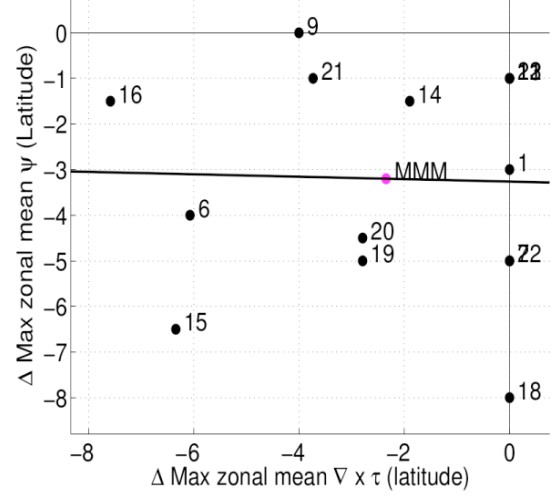

Figure 4. As for Figure 3 but for RCP8.5.

Sen Gupta et al., 2009; Wang et al., 2011] and atmospheric studies of CMIP5 (Bracegirdle et al., submitted manuscript, 2012).

[21] The ACC transport through Drake Passage changes considerably relative to historical internal interannual variability under the climate forcing scenarios in many models, but the change is not in a consistent direction in either RCP4.5 or RCP8.5 $(-1.9 \pm 10.1 \mathrm{~Sv}$ and $-2.7 \pm 9.8 \mathrm{~Sv}$ respectively, Table 2). This is consistent with the CMIP3 results [Sen Gupta et al., 2009], although again the range of model responses is reduced compared with CMIP3 (maximum changes of $-29.9 \mathrm{~Sv}$ to $+27.4 \mathrm{~Sv}$ ). Interestingly, the greatest changes occur in the RCP4.5 scenario $(-26 \mathrm{~Sv}$, HadGEM2-CC to +17 Sv, INMCM4). The change in Drake Passage transport is almost completely uncorrelated with either the change in maximum mean zonal wind stress or its latitude under RCP4.5 (Figures 3b, 3c, and 3d). There are slightly stronger positive correlations between maximum zonal wind stress (particularly wind stress in the direction of the ACC streamlines) and Drake Passage transport under RCP8.5 (Figures $4 \mathrm{~b}$ and $4 \mathrm{c}$ ), but they are still statistically insignificant at the $90 \%$ confidence level. There is considerable model spread and several models with large ACC transport changes have wind stress changes less than the multi model mean. Wang et al. [2011] found a similar lack of correlation in the CMIP3 models, although the correlations are even weaker in CMIP5.

[22] Like the ACC transport, the change in position of the ACC core varies significantly between models under both RCP4.5 and RCP8.5, with a mean shift of $0.07 \pm 0.36^{\circ}$ and 
$-0.01 \pm 0.44^{\circ}$ respectively (Table 2 ). There is a statistically significant $(p<0.009)$ negative correlation between the change in ACC strength and the mean ACC latitude, with those models with an increasing (decreasing) transport having a poleward (equatorward) ACC shift. This relationship is strongest under the RCP8.5 scenario, with poleward mean shifts of over $0.5^{\circ}$ for IPSL-CM5A-LR, IPSL-CM5A-MR and NorESM1-M. The variable shift in ACC position, and particularly the number of models with equatorwards shifts contrasts with CMIP3 where Fyfe and Saenko [2006] and Sen Gupta et al. [2009] both showed a relatively robust poleward movement of the ACC over the same period. Out of fifteen CMIP3 models examined by Sen Gupta et al. [2009], only four showed an equatorward shift, while eight moved polewards by over $1^{\circ}$. In CMIP5 the situation is reversed and under RCP8.5 only four models have a poleward ACC shift and eleven move equatorwards. Significantly, the magnitude of ACC position shift is much reduced in CMIP5 and no shifts in either direction exceed $1^{\circ}$, while in CMIP3 the ACC moved by almost $4^{\circ}$ in some models. The position of the ACC core appears to be uncorrelated with either the change in zonal mean wind stress or the latitude of the zonal wind jet under either scenario (Figures 3, 4e, and 4f). This again differs from the CMIP3 analysis of Sen Gupta et al. [2009] who found a positive correlation between the wind jet and ACC core latitudes. This is despite consistent and significant changes to the wind stress magnitude and position in all models under RCP8.5 of similar magnitudes to those in CMIP3. The relationship between ACC strength changes and the ACC core position is explored further in section 3.2.

[23] In both RCP4.5 and RCP8.5 scenarios the maximum zonal mean wind stress curl increases uniformly across almost all models $\left(0.5 \pm 0.37 \times 10^{-8} \mathrm{Nm}^{-3}\right.$ and $1.10 \pm 0.40 \times$ $10^{-8} \mathrm{Nm}^{-3}$ respectively), with only CCSM4 and CSIRO-Mk36-0 showing a (small) decrease under RCP4.5. The change under RCP 8.5 is significant at the $90 \%$ level, and is very large compared with the historical internal variability of the models (Tables 2 and 3). This agrees with the change observed in CMIP3 by Wang et al. [2011], but the positive correlation observed in that study between ACC transport and wind stress curl is not observed here in either scenario (Figures 3 and $4 \mathrm{~g}$ ). There is a general increase in the strength of the subtropical gyres in both scenarios $(0.38 \pm 1.74 \mathrm{~Sv}$ and $2.18 \pm 2.81 \mathrm{~Sv}$ respectively), although it is not statistically significant, largely due to the relatively strong reduction in gyre strength $(>2 \mathrm{~Sv})$ in GFDL-ESM2G, IPSL-CM5A-LR and IPSL-CM5A-MR. The general strengthening of the gyres in the RCP4.5 and RCP8.5 scenarios is matched with a large $\left(-1.88 \pm 2.13^{\circ}\right.$ and $-3.20 \pm 2.41^{\circ}$ respectively, Table 2 ) and statistically significant poleward shift in the gyre cores across all models. Although there are robust changes in both the latitude of wind stress curl maximum strength and the latitude of the subtropical gyre cores, they do not appear to be correlated with each other across models (Figures 3 and 4i), in contrast to CMIP3 where there is a strong positive correlation.

\subsection{Horizontal Circulation}

\subsubsection{Historical Representation}

[24] The depth integrated volume transport streamfunction was calculated from the model zonal velocities, as the barotropic mass streamfunction was not available for many of the models. The mean transport streamfunctions are shown for the historical period and the late 21 st century for RCP4.5 (Figure 5) and RCP8.5 (Figure 6), along with the changes in the northern, southern and core positions of the ACC. The core position is calculated as described in section 2, while the northern ACC boundary is the northernmost circumpolar streamline that passes through Drake Passage and the southern is the southernmost circumpolar streamline that passes through Drake Passage in a region of eastward mean depth integrated velocity. In the strongly equivalent barotropic ACC [Killworth and Hughes, 2002] the altimetric sea surface height mean dynamic topography [Rio et al., 2011] provides a reasonable approximation of the barotropic streamfunction and so we may compare this (Figure 6, Observations) with the modeled ACC.

[25] There is broad general agreement on the position and shape of the ACC across most models and with the observations. All show topographically steered eastward flows that divert strongly equatorwards east of Drake Passage, travel eastwards at a roughly constant latitude to around $80^{\circ} \mathrm{E}$ and then turn southwards to pass around Campbell Plateau. The current follows the topography towards the equator around the plateau's eastern side, and then continues south-east until reentering Drake Passage. The only exceptions to this are the GISS-E2-R (Figure 5), where the core of the ACC is biased very strongly south of the observational position and the INMCM4, which has a northern boundary that diverts equatorward as far as Australia. Both of these models appears as outliers in ACC transport and density structure. The position and spatial variability of the ACC core is also reasonably well represented in almost all models, particularly in regions where there are strong topographic controls, such as north of Kerguelen Plateau, around Campbell Plateau and east of Drake Passage. In less topographically constrained regions there is some variability between modeled ACC core positions, notably in the south east Pacific and south east Indian Ocean. The south east Indian Ocean in particular has reasonably high frequency spatial variability in some models (GFDL-ESM-2M, GFDL-ESM2G, CCSM4, NorESM1-M) while being relatively smooth in others (the IPSL and MIROC ensembles), which may be caused by the resolution and representation of the South East Indian Ocean Ridge.

[26] The representation of the subpolar gyres varies significantly between models. This particularly impacts the position of the southern ACC boundary. The eastern edge of the Weddell Gyre between $30-50^{\circ} \mathrm{E}$ and the presence of the shallow Kerguelen plateau is associated with a southward excursion of the ACC southern boundary in the observations, but this is not well replicated by the CNRM-CM5, CSIRO-Mk3-6-0, GFDL-ESM2G, IPSL-CM5A(B)-LR or MRI-CGCM3 models where the southern boundary does not extend polewards of $60^{\circ} \mathrm{S}$. This may be due to the resolution of bathymetry, particularly the Kerguelen plateau, in these models. Due to these differences in the ACC position the Weddell Gyre itself varies greatly, from being practically non existent in the GISS-E2-R to extending to $150^{\circ} \mathrm{E}$ in the MRI-CGCM3. The Ross Gyre is similarly variable and significantly impacts the position of the southern ACC boundary, particularly east of the Pacific Antarctic Ridge at $200^{\circ} \mathrm{E}$. East of this point the southern ACC boundary deflects polewards in several models (CCSM4, CSIRO-Mk3-6-0, GFDL-ESM2M, MRI-CGCM3 and the MIROC suite), as in 

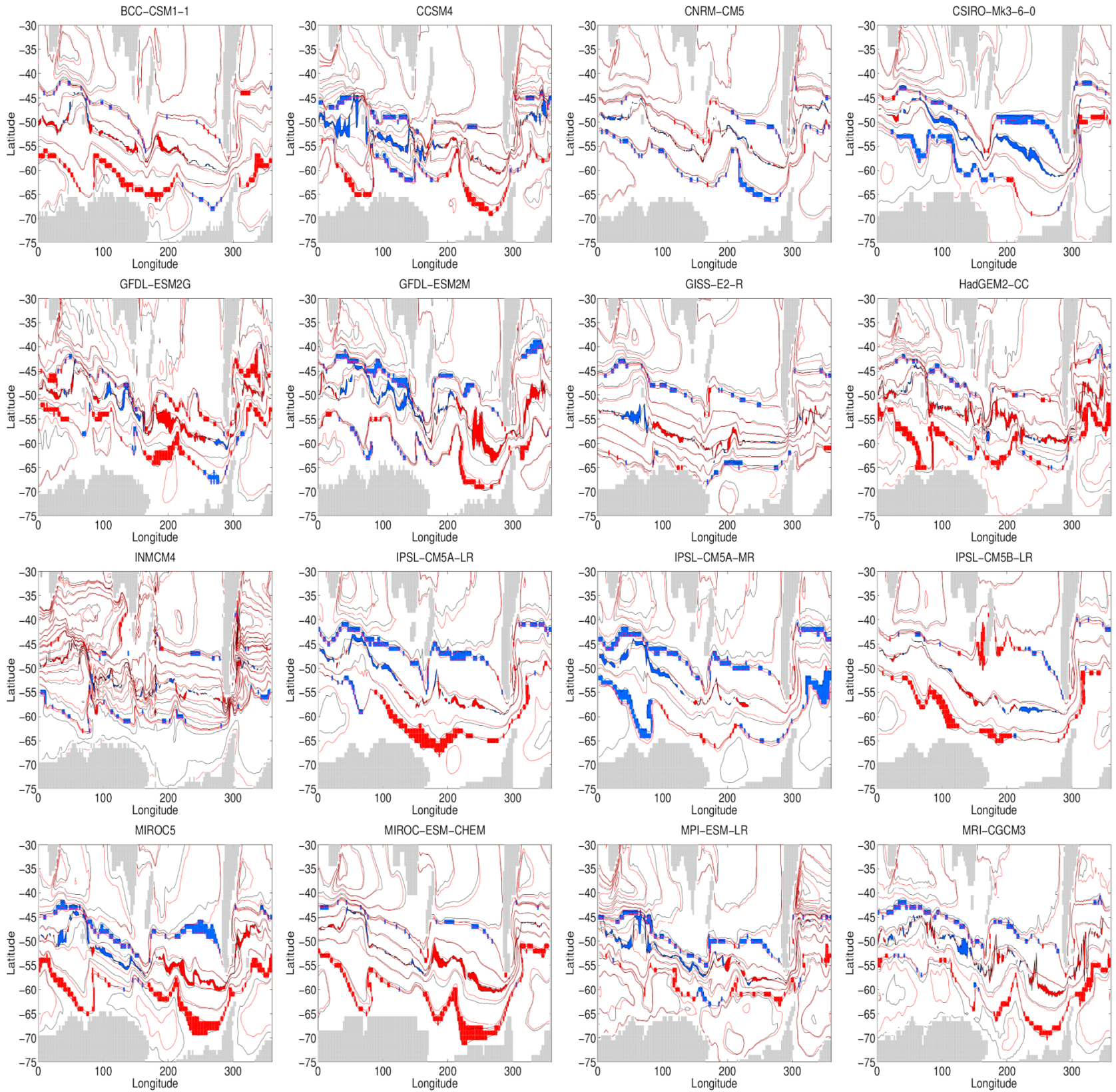

Figure 5. Change in mean streamfunction between historical (black) and RCP4.5 (red) scenarios for selected models. The change in the position of the ACC northern boundary, ACC southern boundary and ACC core between scenarios is shown in blue (red) for poleward (equatorward) movements. Note that in all scenarios South America is set to zero in the streamfunction. Contour intervals are $20 \mathrm{~Sv}$ north of the northern boundary $(0 \mathrm{~Sv})$ and $40 \mathrm{~Sv}$ south of it.

the observations. In others (GISS-E2-R, HadGEM2-CC, HadGEM2-ES, MPI-ESM-LR, and the IPSL suite), however, there is a strong Ross Gyre that keeps the ACC north of $65^{\circ} \mathrm{S}$.

[27] Although not as dramatic, there are also differences between the modeled subtropical gyres. The apparent bimodality of the gyre maxima discussed in section 3.1.1 is largely controlled by the position of the Indian Ocean subtropical gyre, which dominates the streamfunction zonal mean. Those models with zonal mean gyre centers equatorward of $35^{\circ} \mathrm{S}$ (IPSL, MIROC and GFDL suites and MRI-CGCM3, Figure 2) also have Indian Ocean gyre cores equatorward of this point. Those models with poleward gyres centers (Hadley Centre models, NorESM1-M, CCSM4 and MPI-ESM-LR) have gyre centers substantially south of South Africa, and often extend further in a south-easterly direction. This difference in models does not appear to have a large impact on the position of the northern ACC boundary, although models biased southwards do have enhanced Aghulas retroflections that more closely match observations. A tendency for the Indian Ocean gyre to be too far north was noted by Sen Gupta et al. [2009] in CMIP3. There is also some variability in the Pacific where the 

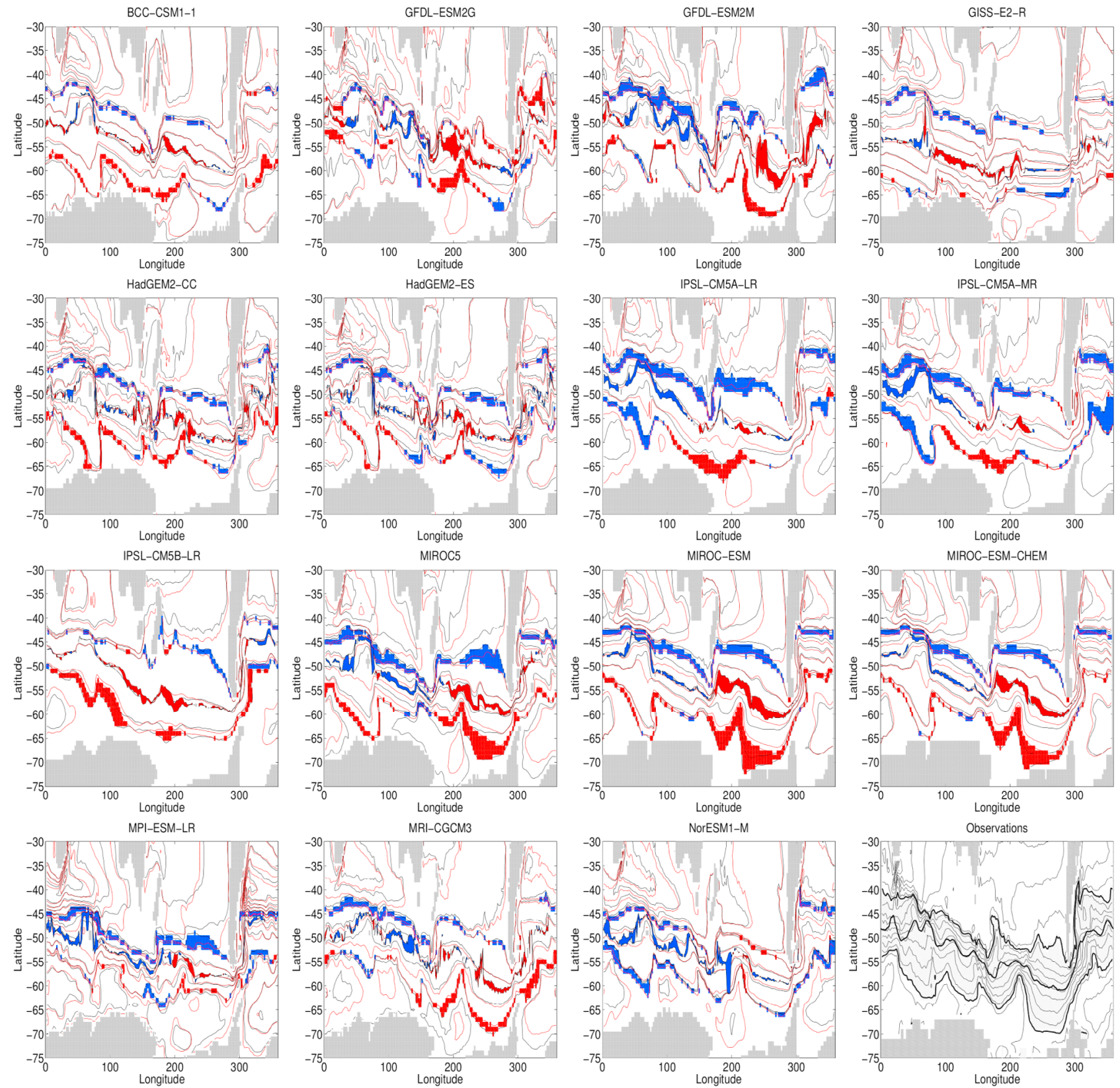

Figure 6. As for Figure 5 but for RCP8.5. Note that the lower right panel shows the AVISO CNESCLS09 mean sea surface height for 1993-1999, which in the ACC closely corresponds to the barotropic streamfunction. The northern and southern boundaries of the ACC are shown in bold, as is the ACC core.

northern boundary of the ACC follows a path further equatorward in most models than in observations. This appears largely due to a failure of the ACC northern boundary to divert sharply southward immediately east of New Zealand, after its short excursion northwards around Campbell Plateau. This is particularly pronounced in the IPSL and MIROC ensembles of models, especially IPSL-CM5B-LR. Bracegirdle et al. (submitted manuscript, 2012) find that in these ensembles the wind stress maxima is strongly biased equatorward in the Pacific, which may explain the northward extension of the ACC here. In these models Sallée et al. (submitted manuscript, 2012a) also find that the Pacific mixed layer maxima, found on the north side of the ACC, is significantly too shallow.

\subsubsection{Changes Under Climate Forcing Scenarios}

[28] Figures 5 and 6 show the shift in the mean streamfunction between the historical and RCP4.5 and RCP8.5 scenarios respectively, along with the change in the ACC core and northern and southern boundaries. The response varies across models, but tends to be very similar between scenarios, with RCP8.5 generally having slightly more accentuated changes than RCP4.5. A robust feature in almost all models is the spin up and southward shift of the subtropical gyres. This occurs approximately evenly in all three basins, and drives the poleward deflection of the northern ACC boundary. This shift may be up to five degrees, and is strongest in the MIROC and IPSL suites and 
a) (r.p): $0.39,0.0074$
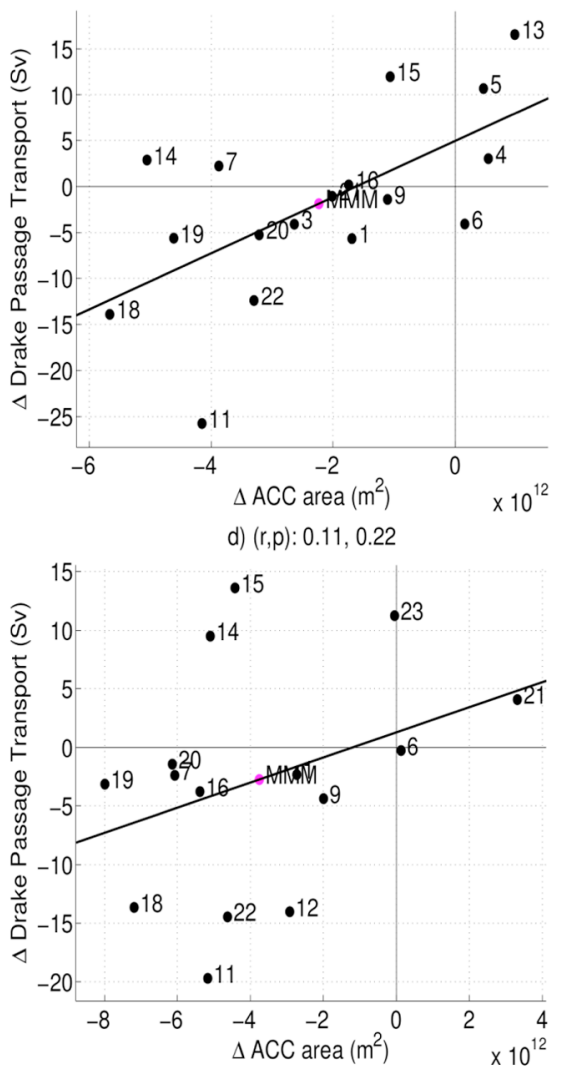

b) $(r, \quad 0.67,6.5 e-05$

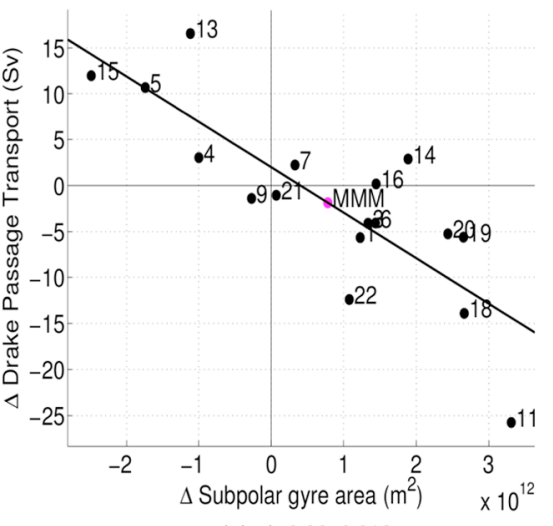

e) $(r, p): 0.39,0.013$

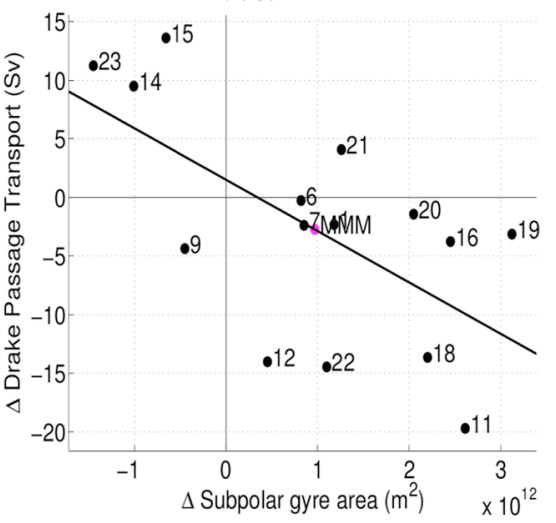

c) $(r, p): 0.0027,0.84$
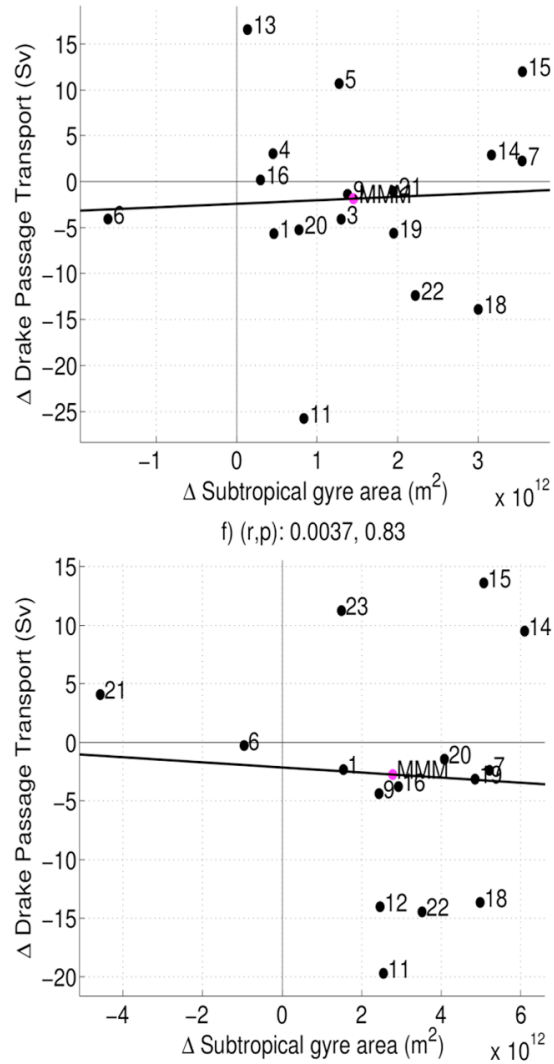

Figure 7. Change in (a) ACC, (b) subtropical and (c) subpolar gyre areas between RCP4.5 and historical scenarios vs change in Drake Passage transport. (d-f) The same but for RCP8.5. Areas calculated as in text.

the GFDL-ESM2M and MPI-ESM-LR models. The only exception to this universal southward shift is the GFDLESM2G in the south west Atlantic, where the ACC expands equatorward in both scenarios.

[29] Generally the ACC core position does not move as much as either the northern or southern boundaries of the ACC, typically less than a few degrees, although the shifts in the MIROC models and GFDL-ESM2M in the Pacific are up to five degrees. It also tends to shift poleward in the Indian sector, and equatorward in the Pacific sector in most models under both scenarios, although some models disagree with this slightly (GISS-E2-R, CSIRO-Mk3-6-0, NorESM1-M). The core generally follows the deflection of the subtropical gyre in the Indian section, and that of the subpolar gyre in the Pacific sector. The equatorward movement of the ACC core in the Pacific sector is different from the general trend in CMIP3, where the majority of models shifted poleward at almost all longitudes [Sen Gupta et al., 2009].

[30] The subpolar gyres change significantly in most models, although the response varies more across models than in the case of the subtropical gyres. In most models the Ross Gyre increases in strength and expands equatorward, by up to five degrees in the case of the MIROC suite of models. Exceptions to this are the CSIRO-Mk3-6-0, CNRM-CM5 and NorESM1-M, which move weakly polewards. The response of the Weddell Gyre is more variable between models, and generally smaller than the changes in the Ross Sea. It expands equatorwards in the BCC-CSM1-1, GFDL-ESM2G, HadGEM2CC, MIROC suite and the MPI-ESM-LR, while shifting polewards in the NorESM1-M, CSIRO-Mk3-6-0 and CNRM-CM5. Interestingly the IPSL-CM5A-LR and IPSLCM5A-MR behave similarly, shifting poleward, while the IPSL-CM5B-LR moves moderately strongly equatorward.

[31] The change in the width of the ACC is driven by the movement of its northern and southern boundaries and was shown to be correlated with the change in Drake Passage transport by Wang et al. [2011] in CMIP3. Figure 7 shows that this is also the case with the CMIP5 ensemble and that weaker (stronger) transports are associated with decreased (increased) ACC areas. This relationship is stronger under RCP4.5 (Figure 7a) than RCP8.5 (Figure 7d), although reasons for this are unclear. The change in the subpolar gyre equatorward extent has a greater correlation with the ACC transport than does the change in subtropical gyre poleward extent in both scenarios. Although almost every model has an increase in mean subtropical gyre area (measured from $30^{\circ} \mathrm{S}$ to the northern ACC boundary) this is not correlated with the change in ACC transport in either scenario (Figures $7 \mathrm{c}$ and $7 \mathrm{f}$ ). The change in subpolar gyre extent (measured from the Antarctic coastline to the southern ACC boundary) is very strongly correlated with the ACC transport in both the RCP4.5 (r,p) = $(0.67,0.00007)$ and RCP8.5 scenarios $(r, p)=(0.39,0.01)$. There is substantially more intermodel spread under RCP8.5, and unlike the case for the subtropical gyres, the change in subpolar gyre areas are not significantly larger under RCP8.5 than RCP4.5. This is probably because they are not as directly controlled by winds as the subtropical gyres. 


\subsection{Meridional Density Structure}

\subsubsection{Historical Skill}

[32] The transport of the ACC is driven by the strong meridional density gradient that separates the relatively warm and saline subtropical gyres from the colder and fresher subpolar gyres. In this section we examine the mean zonal meridional density structure of the CMIP5 ensemble under the historical scenario, and changes between this and the end of the 21st century under the RCP4.5 and RCP8.5 scenarios. While all models reproduce the meridional density gradient associated with the ACC in their mean zonal potential density anomaly fields (Figure 8, Observations) there is considerable variability between them and the observational values (Figure 8). Several models have extremely strong density gradients across the core ACC latitudes $\left(45-60^{\circ} \mathrm{S}\right)$ and strong vertical density gradients to the south of this. The GISS-E2-R, HadCM3 and INMCM4 standout, with the GISS-E2-R in particular having nearly vertical isopycnals down to $1000 \mathrm{~m}$ near $55^{\circ} \mathrm{S}$. These steeply sloped isopycnals drive the very strong ACCs observed in these models and, as would be expected, there is a strong correlation between the meridional density difference (the mean density difference between the latitudes of $42-45^{\circ} \mathrm{S}$ and $62-65^{\circ} \mathrm{S}$, as in Kuhlbrodt et al. [2012]) and the Drake Passage transport (Figure 11a). While the mean density difference $\left(0.24 \mathrm{kgm}^{-3}\right)$ is similar to the observed value $\left(0.23 \mathrm{kgm}^{-3}\right)$, there is a very wide intermodel range $\left(0.12-0.52 \mathrm{kgm}^{-3}\right)$ that reflects the variability between model density structures.

[33] There are also significant differences between models in the vertical stratification south of $60^{\circ} \mathrm{S}$. The BCC-CSM1-1, GFDL-ESM2M, MIROC5 and MPI-ESM-LR all have weak vertical density gradients in the upper $1000 \mathrm{~m}$, while the MRICGCM3 has very strong vertical gradients in the upper $200 \mathrm{~m}$ all the way to the Antarctic coast. The difficulty associated with simulating the formation and export of $\mathrm{AABW}$ and complex ice-ocean interactions may explain the difference in the density structures south of the ACC. North of the ACC there are also differences between models and the observations. Most models are biased too light, with the $35.5 \mathrm{kgm}^{-3}$ contour extending 100-200 m below the observational maxima of $400 \mathrm{~m}$ (e.g., MIROC5, CanESM2, HadGEM2-ES, MPI-ESM-LR). In a companion paper Sallée et al. (submitted manuscript, 2012b) note that the density bias is driven by a strong warm bias and that consequently the potential vorticity minimum characteristic of SubAntarctic Mode Water is poorly represented in most models.

\subsubsection{Changes Under Climate Forcing}

[34] Under both the RCP4.5 and RCP8.5 scenarios there are substantial changes to the meridional density structure by the end of the 21 st century (Figures 9 and 10). The pattern is quite similar under both RCP4.5 and RCP8.5 in all models, but the magnitude of the change is larger under RCP8.5, particularly the lightening trends. In all models there is a significant reduction in density in the upper $1000 \mathrm{~m}$ of the water column. This lightening is strongest on the northern flank of the ACC in the latitude range $40-50^{\circ} \mathrm{S}$ with changes of up to $-0.4 \mathrm{kgm}^{-3}$ over the surface $600 \mathrm{~m}$, associated with mode and intermediate water masses. In the latitude range between $65-80^{\circ} \mathrm{S}$, south of the ACC, there is also a strong reduction in density extending to below $2000 \mathrm{~m}$ in some models (e.g., BCC-CSM1-1, Hadley Center models and MIROC-ESM). In the latitude range associated with the upwelling of circumpolar deep water (CDW) the change in density is smaller in many models, suggesting that the change is driven by surface forcing and subducted deeper into the water column in regions where water masses sink (north of the ACC and in regions of deep winter convection near the Antarctic continent). The presence of weakly modified upwelling CDW is clearest in the CCSM4, GFDLESM2G, HadGEM2-CC, MIROC5 and MRI-CGCM3. Few models have an increase in density anywhere under RCP4.5 (CanESM2, INMCM4, CSIRO-Mk3-6-0, IPSL-CM5A-MR and GFDL-ESM2M) and only one (CanESM2) under RCP8.5. The regions that do increase in density tend to be near the surface south of $60^{\circ} \mathrm{S}$ which then spread northwards at depth, often reducing in magnitude. Sallée et al. (submitted manuscript, 2012b) investigate these changes and suggest that the increase in density is due to salinification.

[35] Because the greatest change in density occurs on the northern side of the ACC in the upper $1000 \mathrm{~m}$ (due to warming (Sallée et al., submitted manuscript, 2012b)) this increases the meridional density gradient across the ACC (Figures $11 \mathrm{~b}$ and 11c). This is universal across all models, although again there is substantial intermodel variability. The mean change is $0.032 \pm 0.010 \mathrm{kgm}^{-3}$ under RCP4.5 and $0.051 \pm 0.013 \mathrm{kgm}^{-3}$ under RCP8.5. Unsurprisingly, there is a statistically significant correlation between the change in meridional density gradient and Drake Passage transport in both RCP4.5 and RCP8.5 $(\mathrm{p}=0.02$ and 0.07 respectively). The fact that the meridional density gradient increases in all models but there is a reduction in ACC transport in some may be explained by the change in the ACC width described in section 3.2.2. The changing boundaries of the ACC outside the latitude range used to calculate the density gradient may also explain the relatively low correlations ( $\mathrm{r}=0.3$ and 0.23 ), particularly in RCP8.5 where the changes in the ACC area are large.

\section{Discussion and Conclusions}

[36] We have presented an assessment of 23 CMIP5 models' representations of the present day ACC and relevant metrics, as well as how these metrics change in the future under the RCP4.5 and RCP8.5 forcing scenarios. In the analyzed models there is a general improvement in the representation of the ACC over CMIP3, with both the ACC strength and position having reduced intermodel spread and extreme values. Although improved, there are still large differences between model representations of the ACC strength, with a range of 90 to $264 \mathrm{~Sv}$, and a standard deviation of $51 \mathrm{~Sv}$ about a mean of $155 \mathrm{~Sv}$.

[37] The position and strength biases of the zonal wind stress maximum present in CMIP3 remain a problem for many models in the CMIP5 ensemble. The equatorward bias is mostly dominated by biases in the Indian and Pacific sectors and Bracegirdle et al. (submitted manuscript, 2012) note through an analysis of atmosphere only versions of selected models that the poor wind stress representation may be associated with the representation of the ocean and its coupling with the atmosphere.

[38] In general, there is a weaker intermodel relationship between both the wind stress and position and the ACC strength and position than was observed in CMIP3. In CMIP5 there is only a very weak positive relationship between larger 

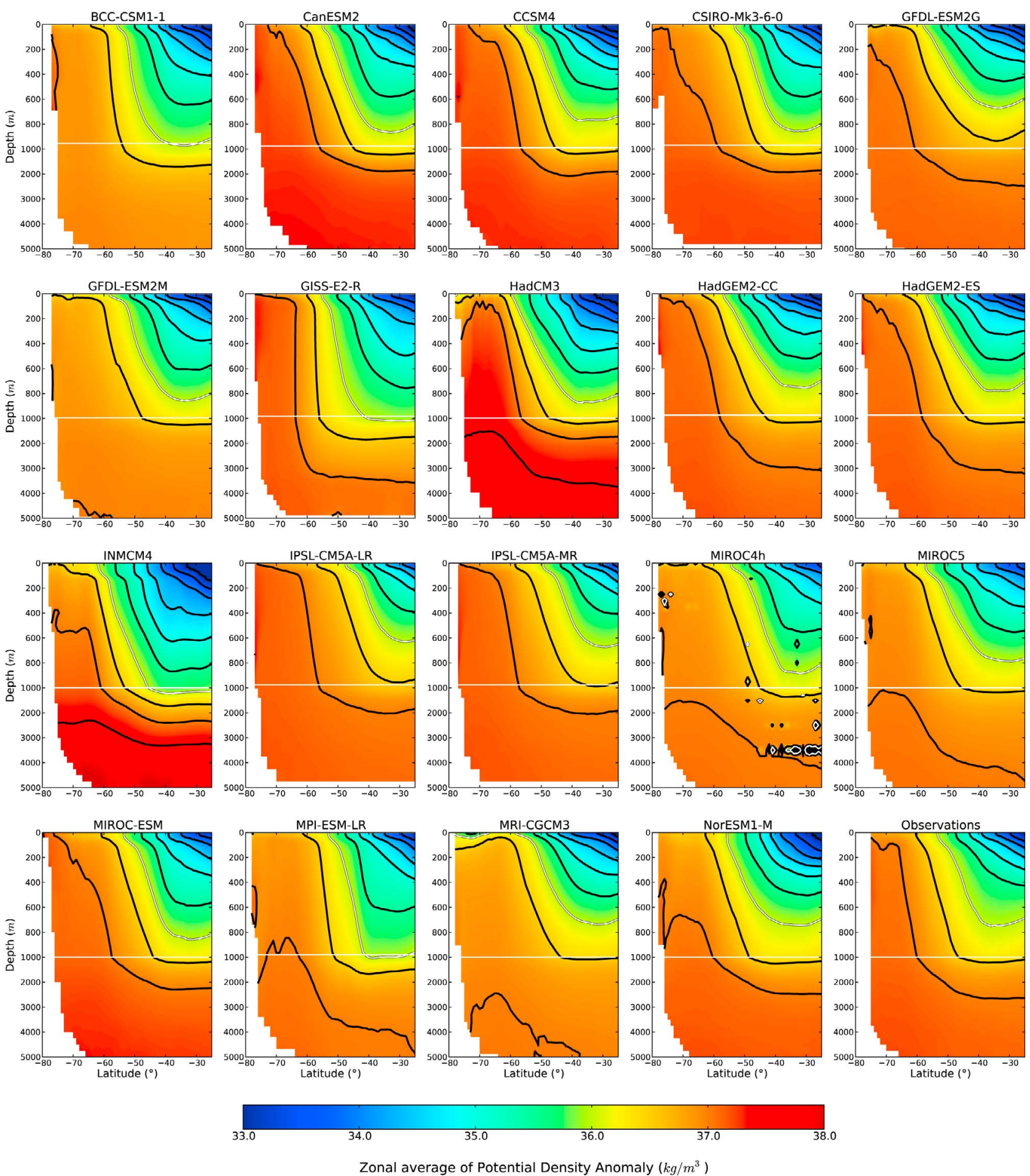

Figure 8. The color bar gives the historical zonal mean potential density anomaly $\left(\sigma_{2}\right)$ for selected models. Observations (lower right panel) taken from CARS09. White contour is $36 \mathrm{kgm}^{-3}$. Contour interval is $0.5 \mathrm{kgm}^{-3}$. Note expanded y-axis for upper $1000 \mathrm{~m}$.

wind stresses and enhanced ACC transport and effectively no relationship between either the position or strength of the wind on the position of the ACC. The weak relationship between the position of the wind and ACC core may be due to the increased ocean resolution in CMIP5 allowing better topographic controls. This is supported by the fact that the largest differences in ACC position between models occurs in the Pacific, where topographic controls are relatively weak, although further investigation is needed to support this supposition. 

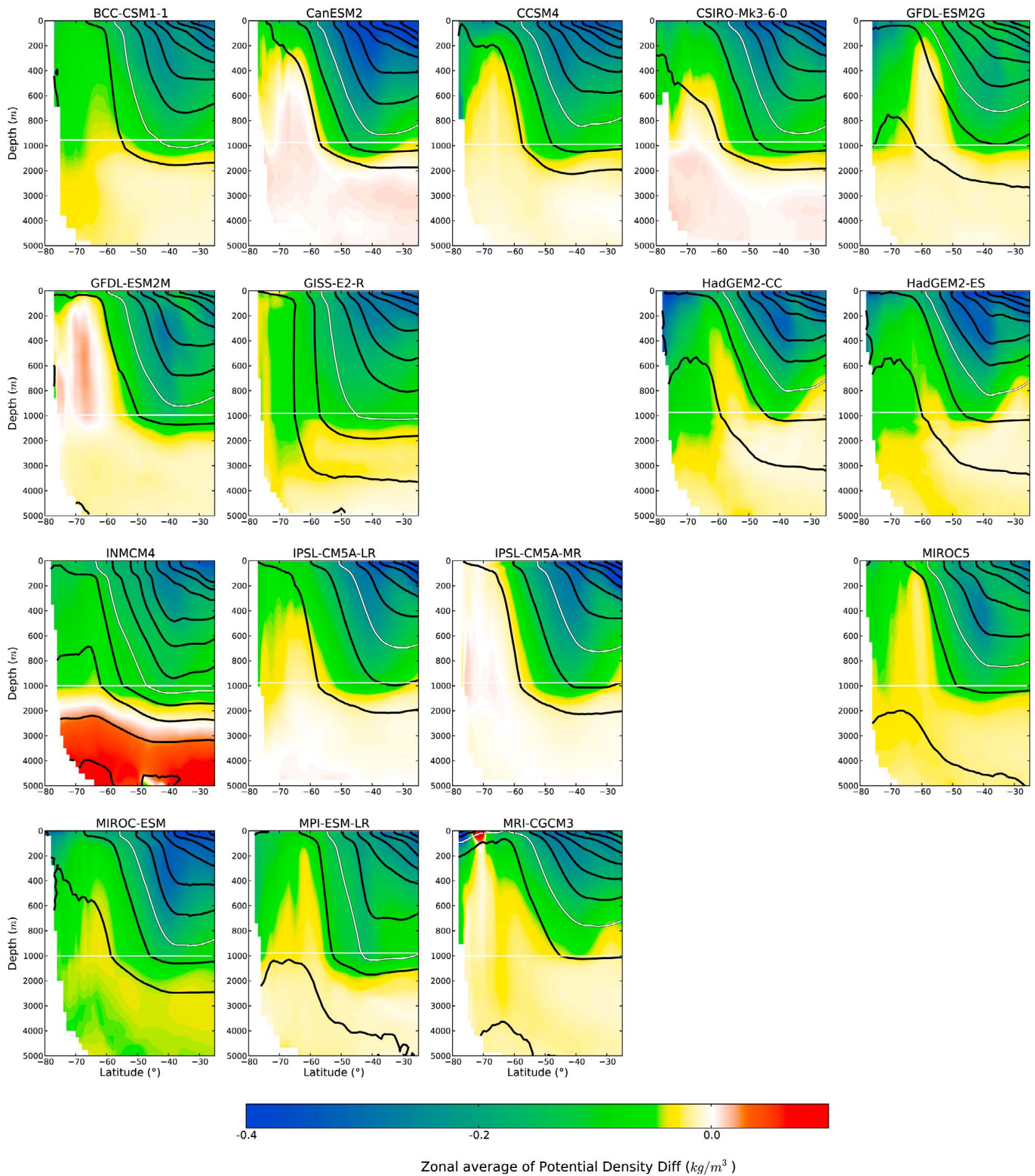

Figure 9. The color bar gives the difference between RCP4.5 and historical zonal mean potential densities $\left(\sigma_{2}\right)$. Contours show RCP4.5 mean zonal potential density anomaly. White contour is $36 \mathrm{kgm}^{-3}$. Contour interval is $0.5 \mathrm{kgm}^{-3}$. Note expanded y-axis for upper $1000 \mathrm{~m}$.

[39] The position of the subtropical gyres partially defines the northern boundary of the ACC, and changes to these have been shown to be important for the position of the ACC [Cai, 2006; Wang et al., 2011]. The strength and position of the wind stress curl maxima in the CMIP5 models tends to be biased too strong and too far equatorward, as may be expected given the similar biases present in the wind stress. The gyres themselves are strongly controlled through the Sverdrup balance by wind stress curl over their respective basins. Given the positive intermodel correlations between the wind stress curl strength and position with the subtropical gyre strength and position it seems reasonable to infer 

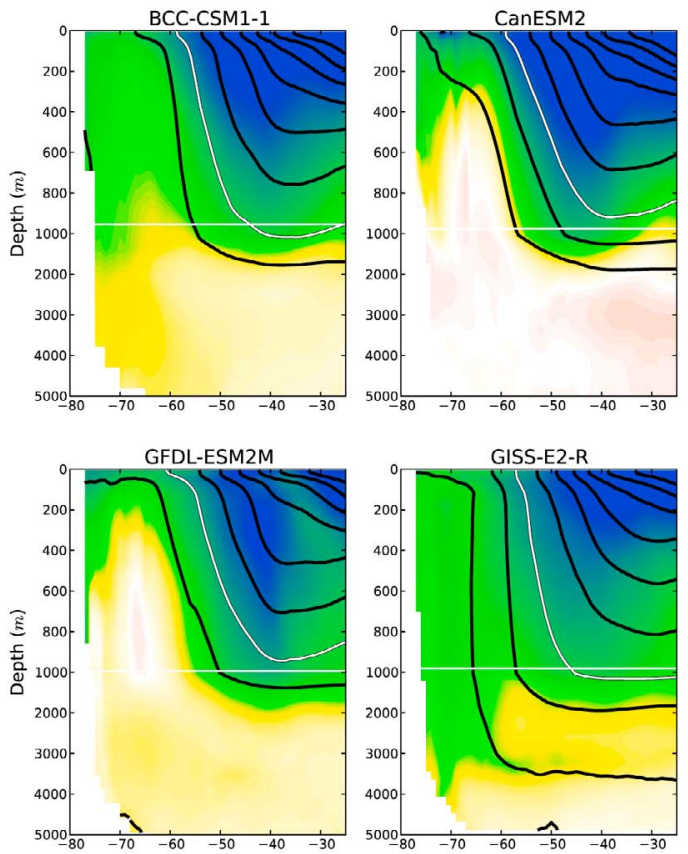

IPSL-CM5A-LR
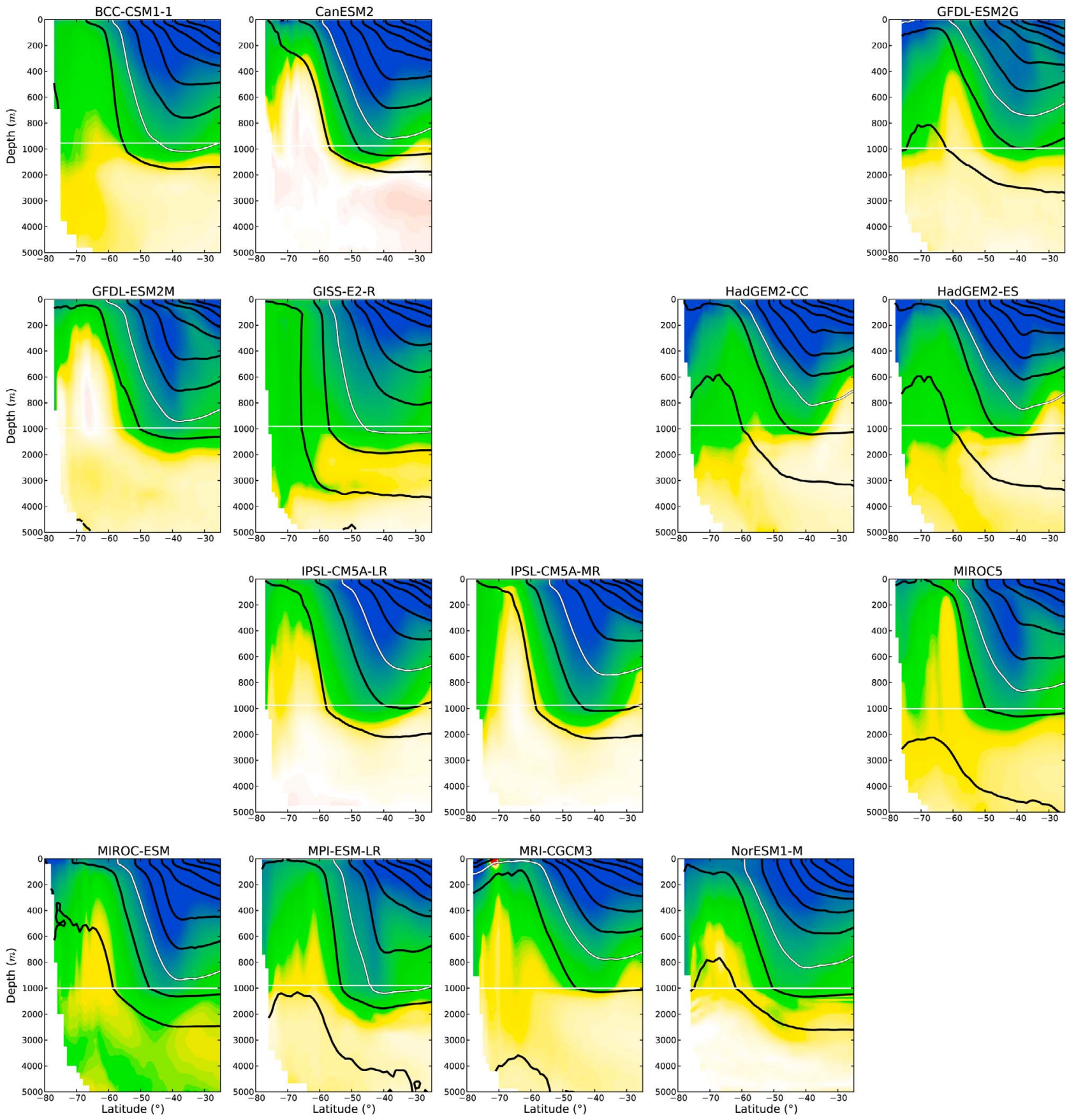

$-0.4$
0.0

Zonal average of Potential Density Diff $\left(\mathrm{kg} / \mathrm{m}^{3}\right)$

Figure 10. As for Figure 9, but for RCP8.5.

that the gyres themselves are probably biased too strong and too far equatorward as well. This is harder to compare with observations as volume transport streamfunctions of the subtropical gyres are difficult to estimate. Sallée et al. (submitted manuscript, 2012a) note that the IPSL and MIROC suites of models tend to have mixed layer depth maxima that are too shallow and too far north in the Pacific. This may be caused by the strong equatorward biases of the subtropical gyres present in these models, and may have implications for the ventilation of the ocean interior in these models.

[40] The CMIP5 models react in a generally similar way to CMIP3 models under climate forcing scenarios. Both the RCP4.5 and RCP8.5 scenarios elicit similar responses, although magnitudes tend to be substantially greater under RCP8.5. The zonal wind stress over the ACC in RCP8.5 

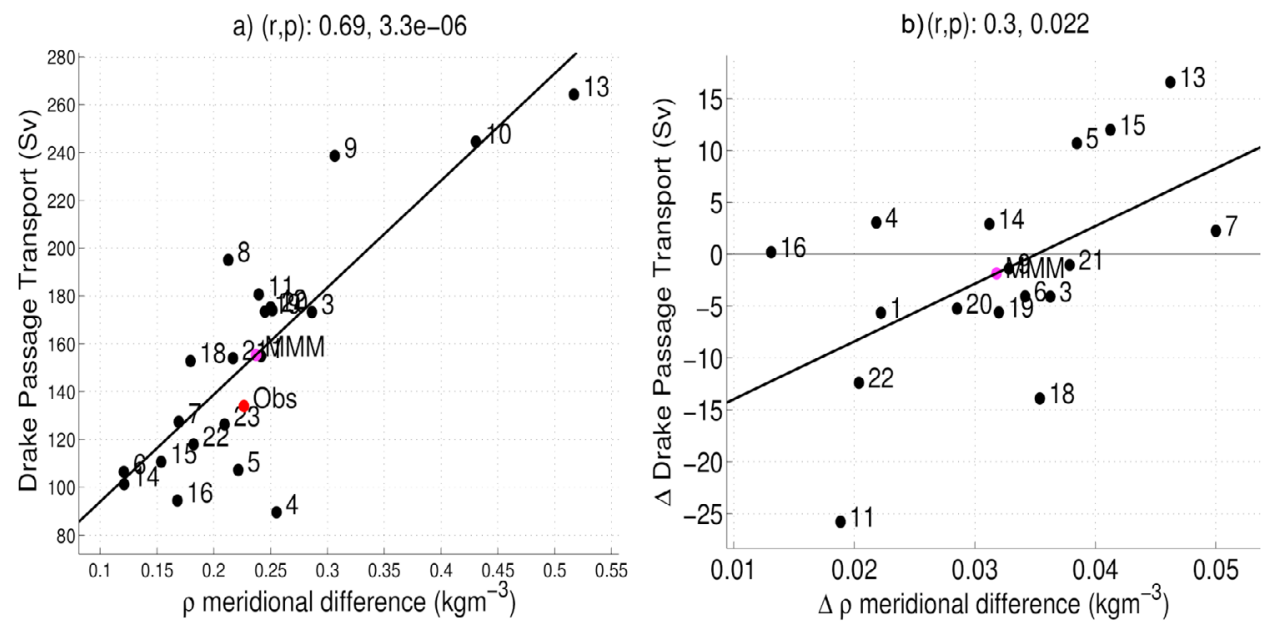

c) $(r, p): 0.23,0.071$

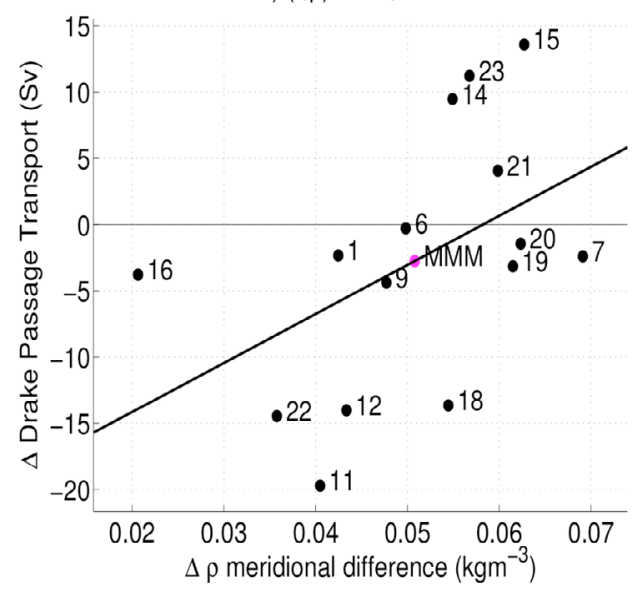

Figure 11. Potential density meridional gradient (difference between mean zonal density at $63-65^{\circ} \mathrm{S}$ and $43-45^{\circ} \mathrm{S}$ ) vs Drake Passage transport for (a) the historical scenario and (b) changes under RCP4.5 and (c) RCP8.5.

almost universally becomes stronger $\left(0.025 \pm 0.008 \mathrm{Nm}^{-3}\right)$ and shifts polewards by $-1.62 \pm 1.36^{\circ}$. Similarly the wind stress curl over the subtropical gyres increases in magnitude and moves substantially poleward $\left(-2.35 \pm 2.69^{\circ}\right)$, which spins up the subtropical gyres and shifts their cores and southern boundaries polewards by a similar amount. This strongly controls the position of the northern ACC boundary, which moves southwards at most longitudes in almost all models. This shift is particularly strong in the Indian and Pacific sectors of the IPSL and MIROC models, which were also noted by Bracegirdle et al. (submitted manuscript, 2012) to have the strongest equatorward biases in wind stress. They note that there is a state dependence of wind stress shifts on the initial bias between the historical wind stress and its observed position. The cause of the wind stress biases in both CMIP3 and CMIP5 are presently unclear. The changes in the northern ACC boundary due to the movement of the subtropical gyres show that these historical biases may have strong implications for changes in the ACC northern boundary and consequently on mixed layer depths and the subduction of water into the ocean interior (Sallée et al., submitted manuscript, 2012a).

[41] As was also observed in the CMIP3 ensemble, there is no uniform response between models in the ACC transport strength [Wang et al., 2011; Sen Gupta et al., 2009]. There are a range of responses of between -26 and $+17 \mathrm{~Sv}$, and there is no significant correlation with the change in wind stress magnitude or latitude. Unlike the CMIP3 response, however, the ACC core position does not uniformly shift polewards. Instead there is a general tendency for the ACC core to move equatorward in the Pacific and poleward in the Indian sector, while changes are generally negligible in the Atlantic sector. The magnitude of changes in the mean ACC latitude are also substantially smaller in CMIP5 than in CMIP3. The zonal mean shift of the ACC core is strongly correlated with the change in Drake Passage transport and stronger (weaker) ACC transports are associated with poleward (equatorward) ACC core movements. Both the strength and position of the ACC changes are strongly correlated with the changes in the position of the southern ACC boundary, driven by changes in the subpolar gyre extents. The dependence of the ACC transport on the change in the subtropical gyre extent was also observed by Wang et al. [2011] in CMIP3 and we see here that although the mean meridional density gradient increases under climate forcing in all models and this is positively correlated with transport, the net transport change is dominated instead by the width of the ACC. 
[42] Both the climatological representation and climate forcing response of the subpolar gyres varies greatly between models. These differences poleward of the ACC are also apparent in the zonal mean density structure, where there are large differences in both the horizontal gradient and vertical stratification between models. This translates into substantial intermodel variability in their response to climate forcing. While there is a general reduction in density in the upper $1000 \mathrm{~m}$ north of the ACC core under both RCP4.5 and RCP8.5, there are more variable changes poleward of this. In some models there is substantial lightening down to below $2000 \mathrm{~m}$ south of $65^{\circ} \mathrm{S}$, while in others the penetration is limited to the surface $500-1000 \mathrm{~m}$. Similarly in some models there is evidence for tongues of upwelling CDW that do not lighten as much in the upper $1000 \mathrm{~m}$, while in other models this is not present. The impact of the historical model state on the response to climate change on these high latitudes and whether or not there is a state dependence, particularly on the vertical stratification, is something that should be investigated in future studies.

[43] The generally poor representation of high latitude density structure and the variable response of the subpolar gyres to climate forcing reflects the difficulties in accurately representing the complex interactions between the ocean, sea-ice, ice shelves and atmosphere in these high latitude regions and the sensitivity of these interactions to the modeled buoyancy fluxes, stratification and mixing. The upwelling of CDW and ventilation of the abyssal layers that occurs at high latitudes, however, is very important for the accurate representation of sea ice, Antarctic mass balance and the Southern Ocean carbon sink [Le Quéré et al., 2007]. The impact of the subtropical and subpolar gyre positions on the ACC position and broader ACC transport demonstrated here may have important implications for the formation and subduction of mode and intermediate waters in these models. The poor representation of the vertical density structure north of the ACC demonstrated by Sallée et al. (submitted manuscript, 2012a) similarly effects the representation of maximum mixed layer depths which are biased consistently too shallow and light. The depth of the mixed layer and intermediate water volumes are critical components for the subduction of surface waters into the deeper ocean and consequently the MOC [Sallée et al., 2012]. Sallée et al. (submitted manuscript, 2012b) demonstrates that the climatologically forced ACC movements in CMIP5 are associated with a reduction in intermediate water volume and outcrop area. This in turn may have significant consequences for the sequestration and transport of heat, freshwater and carbon dioxide, and hence on the broader climate [Sallée et al., 2012].

[44] The wide variety of ACC responses across models to climate forcing, despite a relatively coherent change in the wind stress forcing underscores the need for a greater understanding of how this region is represented and responds to forcing in coupled climate models. The variability in the representation of the meridional density structure, particularly south of the ACC appears to dominate the zonal wind stress in terms of both setting the climatological ACC strength and position, as well as its response to climate forcing. While idealized modeling studies show there is a strong dependence of ACC transport on wind stress in low resolution models, the change in wind stress under climate forcing is relatively small in comparison to both the idealized cases $(<15 \%)$, which may be several multiples of the climatological mean, and the intermodel spread of mean wind stress $(<50 \%)$. Instead changes in surface buoyancy and the rate at which this is transported into the ocean interior appear to dominate the change of the ACC meridional density gradient between models, while the position of the subpolar gyre northern boundary is critical to the net ACC transport. Further investigations of the impact of properties such as surface buoyancy flux, subpolar wind stress curl, vertical stratification and particularly eddy processes on the ACC density structure are needed to understand the representation and changes of this climatically important region.

[45] Acknowledgments. This study is part of the British Antarctic Survey Polar Science for Planet Earth Programme. It was funded by The UK Natural Environment Research Council (grant reference number NE/J005339/1). We acknowledge the World Climate Research Programme's Working Group on Coupled Modeling, which is responsible for CMIP, and we thank the climate modeling groups (listed in Table 1 of this paper) for producing and making available their model output. For CMIP the U.S. Department of Energy's Program for Climate Model Diagnosis and Intercomparison provides coordinating support and led development of software infrastructure in partnership with the Global Organization for Earth System Science Portals. The MDT CNES-CLS09 was produced by CLS Space Oceanography Division and distributed by Aviso, with support from Cnes. Z. Wang was supported by Chinese National Key Basic Research Program (2010CB950301) and by a project funded by the Priority Academic Program Development of Jiangsu Higher Education Institutions (PAPD).

\section{References}

Abernathey, R., J. Marshall, and D. Ferreira (2011), The dependence of Southern Ocean meridional overturning on wind stress, J. Phys. Oceanogr., 41, 2261-2277.

Böning, C., A. Dispert, M. Visbeck, S. Rintoul, and F. Schwarzkopf (2008), The response of the Antarctic Circumpolar Current to recent climate change, Nat. Geosci., 1(12), 864-869.

Bracegirdle, T. J., W. M. Connolley, and J. Turner (2008), Antarctic climate change over the twenty first century, J. Geophys. Res., 113, D03103, doi:10.1029/2007JD008933.

Cai, W. (2006), Antarctic ozone depletion causes an intensification of the Southern Ocean super-gyre circulation, Geophys. Res. Lett., 33, L03712, doi:10.1029/2005GL024911.

Cunningham, S., S. Alderson, B. King, and M. Brandon (2003), Transport and variability of the Antarctic Circumpolar Current in Drake Passage, J. Geophys. Res., 108(C5), 8084, doi:10.1029/2001JC001147.

Farneti, R., T. L. Delworth, A. J. Rosati, S. M. Griffies, and F. Zeng (2010), The role of mesoscale eddies in the rectification of the Southern Ocean response to climate change, J. Phys. Oceanogr., 40(7), 1539-1557.

Fyfe, J., and O. Saenko (2006), Simulated changes in the extratropical Southern Hemisphere winds and currents, Geophys. Res. Lett., 33, L06701, doi:10.1029/2005GL025332.

Gent, P., and J. McWilliams (1990), Isopycnal mixing in ocean circulation models, J. Phys. Oceanogr., 20, 150-155.

Gille, S. (2008), Decadal-scale temperature trends in the southern hemisphere ocean, J. Clim., 21, 4749-4765.

Griesel, A., M. R. Mazloff, and S. T. Gille (2012), Mean dynamic topography in the Southern Ocean: Evaluating Antarctic Circumpolar Current transport, J. Geophys. Res., 117, C01020, doi:10.1029/2011JC007573.

Hallberg, R., and A. Gnanadesikan (2006), The role of eddies in determining the structure and response of the wind-driven southern hemisphere overturning: Results from the modeling eddies in the Southern Ocean (MESO) project, J. Phys. Oceanogr., 36, 2232-2252.

Helm, K., N. Bindoff, and J. Church (2010), Changes in the global hydrologicalcycle inferred from ocean salinity, Geophys. Res. Lett., 37, L18701, doi:10.1029/2010GL044222.

Hogg, A. M., and J. R. Blundell (2006), Interdecadal variability of the Southern Ocean, J. Phys. Oceanogr., 36, 1626-1645.

Ivchenko, V. O., K. J. Richards, and D. P. Stevens (1996), The dynamics of the Antarctic Circumpolar Current, J. Phys. Oceanogr., 26, 754-774.

Killworth, P., and C. Hughes (2002), The Antarctic Circumpolar Current as a free equivalent-barotropic jet, J. Mar. Res., 60, 19-45.

Kuhlbrodt, T., R. Smith, Z. Wang, and J. Gregory (2012), The infuence of eddy parameterizations on the transport of the antarctic circumpolar current in coupled climate models, Ocean Modell., 52-53, 1-8.

Large, W., and S. Yeager (2012), The global climatology of an interannually varying air-sea flux data set, Clim. Dyn., 33, 341-364. 
Le Quéré, C., et al. (2007), Saturation of the Southern Ocean $\mathrm{CO}_{2}$ sink due to recent climate change, Science, 316, 1735-1738.

Marshall, G. (2003), Trend in the southern annular mode from observations and reanalyses, J. Clim., 16, 4134-4143.

Marshall, J., and T. Radko (2003), Residual-mean solutions for the Antarctic Circumpolar Current and its associated overturning circulation, J. Phys. Oceanogr., 33, 2341

Marshall, J., and K. Speer (2012), Closure of the meridional overturning circulation through Southern Ocean upwelling, Nat. Geosci., 5, 171-180.

Meehl, G., et al. (2007), The WCRP CMIP3 multi-model dataset: A new era in climate change research Bulletin of the American Meteorological Society, Bull. Am. Meteorol. Soc., 88, 1383-1394.

Meijers, A., N. Bindoff, and S. Rintoul (2011), Frontal movements and property fluxes: Contributions to heat and freshwater trends in the Southern Ocean, J. Geophys. Res., 116, C08024, doi:10.1029/2010JC006832.

Meinshausen, M., et al. (2011), The RCP greenhouse gas concentrations and their extensions from 1765 to 2300, Clim. Change, 109, 213-241.

Meredith, M., P. Woodworth, C. Hughes, and V. Stepanov (2004), Changes in the ocean transport through Drake Passage during the 1980s and 1990s, forced by changes in the Southern Annular Mode, Geophys. Res. Lett., 31, L21305, doi:10.1029/2004GL021169.

Meredith, M., A. C. Naveira-Garabato, A. Hogg, and R. Farneti (2012), Sensitivity of the overturning circulation in the Southern Ocean to decadal changes in wind forcing, J. Clim., 25, 99-110.

Mignone, B., A. Gnanadesikan, J. Sarmiento, and R. Slater (2006), Central role of Southern Hemisphere winds and eddies in modulating the oceanic uptake of anthropogenic carbon, Geophys. Res. Lett., 33, L01604, doi:10.1029/2005GL024464.

Morrison, A., A. M. Hogg, and M. L. Ward (2011), Sensitivity of the Southern Ocean overturning circulation to surface buoyancy forcing, Geophys. Res. Lett., 38, L14602, doi:10.1029/2011GL048031.

Moss, R., et al. (2010), The next generation of scenarios for climate change research and assessment, Nature, 463, 747-756.

Purkey, S., and G. C. Johnson (2010), Warming of global abyssal and deep Southern Ocean waters between the 1990s and 2000s, J. Clim., 23, 6336-6351.

Ridgway, K., J. Dunn, and J. Wilkin (2002), Ocean interpolation by fourdimensional weighted least squares-Application to the waters around Australasia, J. Atmos. Oceanic Technol., 19(9), 1357-1375.
Rintoul, S. (2007), Rapid freshening of Antarctic Bottom Water formed in the Indian and Pacific oceans, Geophys. Res. Lett., 34, L06606, doi:10.1029/ 2006GL028550.

Rintoul, S., and S. Sokolov (2001), Baroclinic transport variability of the Antarctic Circumpolar Current south of Australia (WOCE repeat section SR3), J. Geophys. Res., 106, 2815-2832.

Rio, M-H., S. Guinehut, and G. Larnicol (2011), New CNES-CLS09 global mean dynamic topography computed from the combination of GRACE data, altimetry, and in situ measurements, J. Geophys. Res., 116, C07018, doi:10.1029/2010JC006505.

Roemmich, D., J. Gilson, R. Davis, and P. Sutton (2007), Decadal spinup of the South Pacific subtropical gyre, J. Phys. Oceanogr., 37, 162-173.

Russell, J., R. Stougger, and K. Dixon (2006), Intercomparison of the Southern Ocean circulations in IPCC coupled model control simulations, J. Clim., 19, 4560-4575.

Sabine, C., et al. (2004), The oceanic sink for anthropogenic $\mathrm{CO}_{2}$, Science, 305 (5682), 367-371.

Sallée, J.-B., R. Matear, S. R. Rintoul, and A. Lenton (2012), Localized subduction of anthropogenic carbon dioxide in the Southern Hemisphere oceans, Nat. Geosci., 5, 579-584, doi:10.1038/ngeo1523.

Sen Gupta, A., A. Santoso, A. S. Taschetto, C. C. Ummenhofer, J. Trevena, and M. H. England (2009), Projected changes to the Southern Hemisphere ocean and sea ice in the IPCC AR4 climate models, J. Clim., 22, 3047-3078.

Sokolov, S., and S. Rintoul (2009), The circumpolar structure and distribution of the Antarctic Circumpolar Current fronts: 1. Mean circumpolar paths, J. Geophys. Res., 114, C11018, doi:10.1029/2008JC005108.

Solomon, S., D. Qin, M. Manning, Z. Chen, M. Marquis, K. Averyt, M. Tignor, and H. Miller (Eds.) (2007), Climate Change 2007: The Physical Science Basis: Working Group I Contribution to the Fourth Assessment Report of the IPCC, Cambridge Univ. Press, New York.

Taylor, K., R. Stouffer, and G. Meehl (2012), An overview of CMIP5 and the experiment design, Bull. Am. Meteorol. Soc., 93, 485-498.

Wang, Z., T. Kuhlbrodt, and M. P. Meredith (2011), On the response of the antarctic circumpolar current transport to climate change in coupled climate models, J. Geophys. Res., 116, C08011, doi:10.1029/2010JC006757. 